\title{
Tamanho da Escola: qual é o mais efetivo e para quem?*
}

\author{
VALERIE E. LEE \\ Ph.D., Professora da School of Education, University of Michigan, Ann Arbor, \\ Michigan, especialista em Sociologia da Educação e Metodologia Estatística. \\ vlee@umich.edu \\ JULIA B. SMITH \\ Professora Assistente do Department of Learning and Leadership da Western \\ Michigan University, Kalamazoo, Michigan.
}

\begin{abstract}
Resumo
Neste estudo investiga-se a relação entre a aprendizagem e o tamanho da escola de nível médio nos E.U.A. Foram estudadas três levas de dados coletados na pesquisa do National Educational Longitudinal Study de 1988 (NELS: 88) e utilizados modelos hierárquicos lineares, com o HLM, para verificar como o desenvolvimento do desempenho dos estudantes em leitura e matemática, durante os anos da escola média, é influenciado pelo tamanho da escola que freqüentam. A pesquisa focalizou três questões centrais: (a) "Que tamanho de escola média é o mais efetivo para a aprendizagem dos alunos?", (b) "Em que tamanho de escola a aprendizagem é distribuída de modo mais eqüitativo?", (c) "São os efeitos do tamanho distribuídos consistentemente por escolas que diferem em sua composição social?". Os resultados sugerem que, em termos de efetividade em relação à aprendizagem, a escola ideal tem matriculados entre 600 e 900 alunos. Nas escolas com matrícula abaixo desse número, o desempenho dos alunos em termos de aprendizagem é inferior; e aqueles que freqüentam escolas com matrícula acima dessa, especialmente acima de 2100, têm desempenho consideravelmente inferior. Definindo equidade em termos da relação entre aprendizagem e nível socioeconômico (SES) dos alunos, o estudo verificou que a aprendizagem é distribuída mais eqüitativamente em escolas muito pequenas. Destaca-se uma verificação importante deste estudo: a influência do tamanho da escola é diferente conforme as escolas variam quanto ao nível socioeconômico (SES) dos alunos matriculados e essa influência também é diferente conforme as escolas apresentam diferentes proporções de matriculados pertencentes a minorias sociais. $\mathrm{O}$ tamanho da escola tem efeito mais forte sobre a aprendizagem em escolas com concentração de alunos de baixo nível socioeconômico, assim como nas escolas com maior concentração de alunos de minorias sociais. A discussão dos resultados do estudo focaliza implicações relativas à política educacional.
\end{abstract}

Palavras-chave: Tamanho da escola e aprendizagem, modelos hierárquicos lineares, desempenho em leitura e matemática, composição social, nível sócio-econômico.

* Artigo original publicado em inglês na Educational Evaluation and Policy Analysis, Fall 1997, Vol. 19, No. 3, pp.205-227. "Copyright 1996 by the American Educational Research Association. Reprinted and Translated with permission of the publisher". Com os agradecimentos da Fundação Carlos Chagas à American Educational Research Association e à Educational Evaluation and Policy Analysis pela licença para tradução e publicação deste artigo. Tradução de Nícia M. Bessa, PhD. 


\title{
Resumen
}

Este estudio se propone a investigar la relación entre el aprendizaje y el tamaño de la escuela de la Secundaria en los E.U.A. Para eso, se estudiaron tres conjuntos de datos colectados en la pesquisa del National Educational Longitudinal Study de 1998 (NELS:88) y fueron utilizados modelos jerárquicos lineares, como el HLM, para verificar como el desarrollo del desempeño de los estudiantes en lectura y matemáticas es influenciado por el tamaño de la escuela que atienden, durante los años de la secundaria. Fueron enfocadas tres cuestiones centrales: (a) "Cual tamaño de escuela secundaria es más efectivo en el aprendizaje de los alumnos?" (b) "En que tamaño de escuela el aprendizaje es distribuido más por igual?" (c) "Son los efectos del tamaño consistentemente distribuidos por escuelas que diferencian en su composición social?" . En términos de efectividad en respecto al aprendizaje, los resultados sugieren que la escuela tiene matriculados entre 600 y 900 alumnos. Por otro lado, para las escuelas con matriculados inferior a ese numero, el desempeño de los mismos en el aprendizaje es menor; y para las escuelas con matriculados superior a ese numero, especialmente con más de 2.100 alumnos, el desempeño es considerablemente inferior. El estudio verifica que el aprendizaje es distribuido mas equitativamente en escuelas muy pequeñas, definiendo equidad como la relación entre aprendizaje y nivel económico social (SES). En destaque se verifica que la influencia del tamaño de la escuela es distinta según el nivel socio económico (SES) de sus alumnos y según las distintas proporciones de matriculados que pertenecen a minorías sociales. Para las escuelas con concentración de alumnos de bajo nivel socio económico, su tamaño tiene más efecto sobre el aprendizaje, tal como en las escuelas con un gran numero de alumnos de minorías sociales. Implicaciones para la política educacional son discutidas.

Palabras-clave: Tamaño de la escuela y aprendizaje, modelos jerárquicos lineares, desarrollo en lectura y matemáticas, composición social, nivel socio económico.

\begin{abstract}
The study described in this article investigates the relationship between high school size and student learning. We used three waves of data from NELS:88 and hierarchical linear modeling (HLM) methods to examine how students' achievement growth in two subjects (reading and mathematics) over the high school years is influenced by the size of the high school they attend. Three research questions guided the study: (a) Which size high school is most effective for students' learning?, (b) In which size high school is learning most equitably distributed?, and (c) Are size effects consistent across high schools defined by their social compositions? Results suggest that the ideal high school, defined in terms of effectiveness (i.e., learning), enrolls between 600 and 900 students. In schools smaller than this, students learn less; those in large high schools (especially over 2100) learn considerably less. Learning is more equitable in very small schools, with equity defined by the relationship between learning and student socioeconomic status (SES). An important finding from the study is that the influence of school size on learning is different in schools that enroll students of varying SES and in schools with differing proportions of minorities. Enrollment size has a stronger effect on learning in schools with lower SES students and also in schools with high concentrations of minority students. Implications for educational policy are discussed.
\end{abstract}

Keywords: High school size and learning, hierarchical linear modeling, achievement in reading and mathematics, social composition, socioeconomic status. 
Por que estudar o tamanho da escola média? O presente estudo é uma extensão de trabalhos empíricos e de revisões da literatura realizados anteriormente sobre a estrutura e a organização da escola. Embora uma vertente desse trabalho investigue os efeitos das reformas introduzidas nas escolas (particularmente da reestruturação das escolas) sobre a aprendizagem, resultados de estudos dessa vertente fornecem claras indicações de que os alunos de escolas de menor tamanho aprendem mais e que a aprendizagem é distribuída de modo mais eqüitativo em escolas menores (Bryk, Lee, \& Holland, 1993; Lee, Bryk, \& Smith, 1993, 1995,1996; Lee, Smith, \& Croninger, 1997). Porém, de que tamanho, precisamente, devem ser as pequenas escolas? Seria de esperar que houvesse um ponto em que os resultados fossem reduzidos, um ponto em que a diminuição do tamanho da escola introduziria limitações à oferta de disciplinas escolares e ao nível de competência entre os professores de modo tal que a aprendizagem seria afetada negativamente. Os resultados concernentes ao tamanho das escolas, nas pesquisas sobre sua reestruturação, são relevantes para a política educacional, pois mostram que as escolas de nível médio, em sua maioria, são demasiado grandes para poderem maximizar o desenvolvimento acadêmico de seus alunos. Desafortunadamente, falta a esses estudos especificidade quanto a uma questão bem prática: "Exatamente, qual o tamanho de escola média em que a eficácia é melhor?".

Além do "tamanho ideal", duas outras questões motivam o presente estudo. Ambas focalizam o tema da eqüidade na distribuição da aprendizagem dos alunos. Questiona-se: "O tamanho ideal de escola, definido em termos de otimizar a aprendizagem, também se relaciona a uma distribuição eqüitativa da aprendizagem entre alunos dentro da uma mesma escola?"1. Uma terceira questão focaliza a composição social da escola:- "Os efeitos do tamanho da escola variam conforme o tipo de alunos que as freqüentam?". Exploramos essas questões usando três levas de dados do National Educational Longitudinal Study de 1988 (NELS: 88). Sendo os dados hierárquicos e sendo focalizados os efeitos da escola, empregamos a metodologia mais apropriada: modelos hierárquicos lineares (HLMs).

1 A frase "distribuição social do rendimento escolar" significa, literalmente, a magnitude da diferença em rendimento, em relação a características sociais dos alunos - posição socioeconômica, raça, etnia, gênero. Uma escola na qual essa relação é fraca seria mais eqüitativa no sentido de serem as diferenças em rendimento escolar menos fortemente diferenciadas conforme as características sociais dos alunos. Para uma discussão mais aprofundada do tema, veja-se Bryk, Lee, and Holland (1993) ou Lee \& Bryk $(1988,1989)$. 
O tamanho ótimo da escola tem sido uma questão de constante interesse para a política educacional. "Ótimo" tem sido definido usando-se dois critérios potencialmente conflitantes: (1) como o tamanho da organização afeta os membros do grupo (um critério sociológico); e (2) o melhor tamanho da escola para eficiência econômica ótima (um critério econômico). Embora esses dois objetivos sejam certamente relacionados, alguns pesquisadores têm sugerido que o objetivo de maximizar o desempenho pode levar a escola a afastar-se de um funcionamento eficiente e vice-versa (Goss, 1994; Morrison 1993). Desde a Segunda Guerra Mundial, pelo menos, este tópico tem sido objeto de acalorada discussão nos círculos da política educacional. Essas discussões - que eram muitas vezes motivadas pela necessidade de considerar o problema da "consolidação" de escolas - têm focalizado mais o critério econômico do que o sociológico e claramente têm um viés burocrático. Embora as escolas elementares freqüentemente sejam pequenas, com o intuito de facilitar as relações e oferecer um ambiente de apoio às crianças, pensa-se que as escolas de nível médio devam ser bem maiores para que possam alcançar seus objetivos. O número de alunos em uma escola tanto pode facilitar, como pode dificultar o contato entre seus membros (professores e alunos), afetando importantes relações, seja no domínio acadêmico, seja no domínio social.

Nosso interesse e nossa familiaridade com esse tema emergiram de uma série de estudos patrocinados pelo Center on the Organization and Restruturing of Schools (CORS) na University of Wisconsin. Utilizamos nesses estudos a base de dados do NELS para avaliar os efeitos da reestruturação sobre o desempenho dos alunos, focalizando-o sob dois aspectos: (1) aprendizagem (definida como os ganhos em desempenho durante os anos da escola média) e (2) a distribuição social da aprendizagem (definida pela relação entre a aprendizagem e a origem social das famílias dos alunos). Esses resultados do trabalho escolar estão naturalmente relacionados. Embora aqueles estudos focalizassem aspectos da reestruturação de maior interesse para a missão do CORS (por exemplo: a organização do currículo, o caráter da instrução, o histórico profissional dos professores), também levaram em consideração outros aspectos da estrutura e da composição social das escolas, os quais poderiam oferecer explicações alternativas para os resultados da reestruturação (por exemplo: nível socioeconômico (SES) médio, concentração de minorias sociais, tipo (pública, privada etc.) e tamanho das escolas).

\footnotetext{
* Nota do tradutor - Reunião de escolas de tamanho pequeno, formando uma maior, geralmente em zonas rurais, onde uma escola muito pequena se mostra economicamente ineficiente. 
A princípio, incluímos o tamanho da escola nos modelos analíticos, com o propósito de introduzir um controle estatístico. Entretanto, era marcante a consistência dos efeitos residuais do tamanho da escola sobre os resultados acadêmicos dos alunos. Embora as análises também incluíssem variáveis reconhecidamente relacionadas com o tamanho da escola (tais como tipo da escola, concentração de minorias e várias características da organização social da escola), persistiam os efeitos diretos do tamanho. No decorrer dos cinco anos de vida do CORS, começamos a pensar que esses achados sobre o tamanho da escola tinham uma importância singular. Tanto a eficácia como a equidade mostravam-se mais altas em escolas pequenas. Entretanto, como o tamanho não era um item específico da agenda do CORS, não investigamos mais detidamente o assunto nessa ocasião.

Dentro da estrutura desses estudos, nossa investigação considerou como lineares os efeitos do tamanho. Como a variável tamanho da escola tem uma distribuição assimétrica positiva (com um grande número de escolas pequenas), nós a submetemos a uma transformação logarítmica no caso de análises que requeriam pressupostos rígidos de distribuição normal de variáveis contínuas. Foram encontrados, consistentemente, coeficientes negativos significativos para a relação de "log tamanho" com a aprendizagem dos alunos, o que foi interpretado como "menor é melhor". Reconhecemos, porém, que a relação provavelmente não devia ser linear. Pareceu-nos razoável explorar se não haveria um tamanho "ideal" para a escola de nível médio, em que tanto a eficácia como a equidade fossem maximizadas em termos de determinado resultado escolar. Tem-se um componente adicional de complexidade ao considerar se os efeitos do tamanho da escola são consistentes em relação a alunos de diferentes características e em relação ao desempenho em diversas disciplinas do currículo. Essas são as questões focalizadas no presente trabalho.

\section{Fundamentos da pesquisa}

Argumentos em que se apóia a investigação sobre o tamanho da escola

Duas vertentes de investigação. A pesquisa sobre o tamanho - um aspecto ecológico das organizações educacionais - divide-se em duas categorias. A maioria dos estudos focaliza a escola média. A primeira vertente de pesquisa, que reflete um argumento de economia de escala, focaliza a contribuição potencial do aumento do tamanho das escolas para uma maior economia, através do fortalecimento dos recursos e da diminuição da redundância dos gastos. A segunda vertente dirige a atenção para o modo pelo qual o tamanho influencia outros aspectos 
organizacionais das escolas. À medida que as escolas crescem em matrícula, é natural que se tornem mais formais e burocráticas. Certas conseqüências emergem dessas alterações, inclusive um programa instrucional tipicamente mais diversificado. As conclusões das duas vertentes de pesquisa tomam sentidos opostos: o argumento da eficiência sugere que o aumento do tamanho redunda em benefícios, enquanto o argumento organizacional favorece as escolas menores.

Economia de escala. Ao se estudar organizações que oferecem serviços, o aumento do número de clientes servidos pode redundar em eficiência maior, avaliada segundo dois critérios (Buzacott, 1982). Primeiro, o aumento do número de clientes maximiza a eficiência da prestação de determinado serviço. Por exemplo, se o objetivo de uma escola média é oferecer um currículo apropriado para cada nível de aptidão dos alunos (isto é, avançado, médio, ou básico), então o número maior de alunos contribuiria para maximizar a prestação desse tipo de instrução, já que haveria maior número para formar grupos de alunos de nível de aptidão semelhante. Outros exemplos são concernentes a objetivos de currículos orientados a alunos que têm interesses diferentes, ou necessidades especiais, ou que sejam selecionados segundo outros critérios. Dependendo da importância desses objetivos, a escola deverá contar com alunos em número suficiente para poder sustentar programas separados ou turmas separadas. À medida que o número de alunos com necessidades comuns aumenta, as escolas podem criar mais programas especializados.

O segundo critério relaciona-se a recursos físicos. Suprimentos e materiais requeridos para se oferecer serviços podem ser obtidos mais economicamente quando comprados em larga escala (Buzacott, 1982). Se o custo de suprimentos (tais como papel) é reduzido quando comprados em grande quantidade, ou se outros custos (como eletricidade, ou aquecimento) podem ser mantidos em nível relativamente constante qualquer que seja o número de clientes, então reduz-se a despesa total com custos essenciais quando se tem uma base maior de pessoas e um custopor-pessoa relativamente menor.

O argumento de economia de escala pode ser aplicado ao custo de se "produzir" um certo nível de desempenho dos estudantes. Esse argumento levaria a conclusões que favorecem o maior tamanho das escolas e o movimento de "consolidação" das escolas menores (Kenny, 1982). A lógica se apóia no argumento de que a economia aumenta à medida que os custos essenciais são distribuídos por um número maior de alunos. A quantia poupada pode ser aplicada em expandir a oferta acadêmica feita pela escola no sentido de responder a diferenças individuais quanto a interesses ou a habilidades dos alunos. A aplicação da 
poupança deve resultar seja no reforço dos recursos, seja em maior especialização do programa instrucional, seja em ambas as coisas. Maior especialização do programa instrucional é entendida como uma vantagem nessa vertente de pesquisa. Embora esse argumento presuma que o tamanho maior da escola resulte em maior eficiência operacional (Guthrie,1979; Michelson, 1972), a poupança projetada pelo movimento da "consolidação" das escolas pequenas nunca se materializou (Chambers,1981; Fox,1981). As escolas grandes, em geral, expandem seu pessoal de apoio e seu pessoal administrativo de modo a atender a maiores necessidades burocráticas. Nas áreas rurais (em que a "consolidação" das pequenas escolas continua a ser um tema grandemente discutido) os custos mais altos para distribuir materiais e transportar alunos sobrepassam qualquer poupança (Chambers, 1981).

Há pouca evidência de que o tamanho da escola e os resultados acadêmicos sejam relacionados positivamente, embora Bidwell e Kasarda (1975) tenham encontrado evidência de uma relação indireta. Eles mostraram que a existência de maiores recursos é positivamente e indiretamente relacionada com o desempenho acadêmico, sendo esse efeito mediado pela contratação de professores mais bem preparados e de mais pessoal para apoiar necessidades especiais dos alunos. Nessas investigações, o tamanho das escolas é freqüentemente confundido com o tamanho do distrito escolar, particularmente no caso de escolas de nível médio (pois muitos distritos operam com apenas uma escola de nível médio). A relação entre os recursos disponíveis e tamanho do distrito escolar, não é consistente quando são estudadas diferentes comunidades, dependendo essa relação do nível socioeconômico da comunidade (Friedkin \& Necochea, 1988). Embora em áreas de nível de renda inferior, comumente, os distritos escolares de maior tamanho tenham acesso a maiores recursos do que os distritos menores, a incidência mais alta de "problemas excepcionais" em tais populações introduz limitações, em tais escolas, as quais contribuem para um desempenho acadêmico inferior.

Organização social e acadêmica. Pesquisas recentes atestam a relação entre o tamanho das escolas e a especialização de programas instrucionais. Em geral, maiores escolas têm mais alunos com necessidades semelhantes e, pois, têm mais possibilidade de criar programas específicos para atender a essas necessidades. Pelo contrário, escolas pequenas devem empregar os recursos em programas instrucionais essenciais, ficando os alunos que fogem ao padrão geral (posicionados em qualquer dos extremos de uma distribuição de habilidade geral ou de interesse) sem acesso a programas apropriados ou absorvidos em programas que podem não atender a suas necessidades especiais (Monk, 1987; Monk \& Haller, 1993). De outro lado, 
as pesquisas sobre trilhas curriculares sugerem que a diferenciação dos currículos e a oferta diferenciada de experiências acadêmicas têm resultados desanimadores (Gamoran, 1989; Oakes, 1985). O aumento do tamanho da escola permite a diversificação do currículo, o que resulta em diferenciação de experiências acadêmicas dos alunos e na estratificação social dos resultados expressos no desempenho dos alunos (Lee \& Bryk,1989).

É bom ou não se ter uma crescente diferenciação do currículo? Embora a diversificação de programas se ajuste ao ideal da escola "compreensiva", na qual o objetivo principal é atender às diferenças individuais dos alunos, essa especialização poderia ser encarada de modo diverso, do ponto de vista de uma perspectiva alternativa que focaliza aspectos comuns da aprendizagem. Essa perspectiva tem motivado alguns trabalhos empíricos recentes sobre os efeitos do currículo, ligando a diferenciação das experiências acadêmicas dos alunos à estratificação do desempenho acadêmico (Garet \& DeLaney,1988; Lee \& Bryk,1988, 1989; Lee \& Smith,1993). Escolas públicas e particulares diferem quanto à oferta de programas instrucionais, conforme seja seu tamanho. As escolas católicas aumentam o número de programas instrucionais acadêmicos à medida que seu tamanho aumenta, enquanto as escolas públicas tipicamente introduzem programas de desenvolvimento pessoal e programas em outras áreas não acadêmicas (Bryk et al., 1993).

A teoria sociológica sugere que à medida que uma organização cresce, as interações e os laços entre as pessoas se tornam mais formais (Weber, 1947). Tipicamente, o crescimento organizacional gera novas estruturas burocráticas à medida que as conexões entre os indivíduos se tornam menos pessoais. Essas estruturas, por seu turno, podem inibir a organização do grupo (Bryk \& Driscoll, 1988). Esta hipótese tem recebido apoio em pesquisas que identificam características organizacionais de escolas que apresentam resultados positivos. Em boa parte da literatura sobre a ambiente escolar, por exemplo, o tamanho da escola opera como um aspecto "ecológico" da estrutura social da escola, como parte do ambiente físico ou material que influencia a natureza das interações sociais (Barker \& Gump, 1964; Bryk \& Driscoll, 1988; Garbarino, 1980; Moricco, 1978).

A pesquisa de cunho organizacional conclui que o tamanho menor da escola é benéfico para os alunos em diversos aspectos. O currículo mais limitado, nas escolas médias de menor tamanho, é tipicamente composto de disciplinas acadêmicas, e o resultado é que virtualmente todos os alunos seguem o mesmo programa de estudos, quaisquer que sejam seus interesses, suas habilidades e seu ambiente social de origem. Isto resulta 
tanto em média mais alta de rendimento escolar quanto em rendimento escolar distribuído mais eqüitativamente (Lee \& Bryk, 1988, 1989). As relações sociais são também mais positivas em escolas menores. As evidências sociológicas, preponderantes na pesquisa sobre escolas médias, sugerem que "tamanho menor é melhor" (Lee, Bryk \& Smith, 1993).

Objetivos do presente estudo. Em quaisquer escolas de nível médio observa-se claramente a existência de tensões relacionadas ao número e ao tipo de alunos a que atende. Obviamente, as escolas médias precisam oferecer alguma variedade de opções no currículo, com base nos interesses, nas competências e nos planos de seus alunos para o futuro. Ao expandir numericamente sua população a escola aumenta suas possibilidades de prover tais opções, pois um número maior de alunos significa mais recursos para dar atendimento a diferenças individuais (por exemplo, possibilidade de empregar professores especializados em diferentes disciplinas, número de alunos suficiente para preencher a matrícula em disciplinas opcionais em toda a extensão coberta pelo currículo acadêmico). De outro lado, maior número de alunos significa ter mais problemas, assim como aumenta a necessidade de monitoramento. Desse ponto de vista, limitar o tamanho da escola pode resultar em melhor atendimento às dimensões humanas da educação escolar.

O presente estudo procura fundamentar-se nos trabalhos empíricos e teóricos que discutem ou que investigam a questão do tamanho da escola de nível médio. Embora a maior parte dos estudos tenha tratado do tema sob o ângulo de "maior-versus-menor", nosso objetivo é expandir a investigação, procurando estimar um ponto ótimo de tamanho da escola. Esse ponto é identificado ao se estimar o quanto os alunos aprendem em função do tamanho da escola, embora reconheçamos que, além do rendimento escolar, o tamanho da escola pode refletir-se de modo diverso em outros resultados alcançados pelo trabalho escolar. Nosso primeiro objetivo neste estudo é identificar o tamanho ideal para a escola de nível médio, definido em termos da aprendizagem dos alunos. Um segundo objetivo é definir um tamanho ótimo em termos da distribuição eqüitativa da aprendizagem dentro das escolas. O terceiro objetivo é verificar se o tamanho ideal é o mesmo para todos os tipos de escola média, sendo o tipo de escola definido em termos do ambiente social de origem dos alunos a que serve.

\section{Metodologia \\ Dados}

Amostra. Usamos os três primeiros levantamentos por amostragem do NELS: 88, com dados coletados pelo National Center for Education 
Statistics sobre os mesmos estudantes desde que cursavam a $8^{\text {a }}$ série do ensino fundamental, seguindo-os na $10^{a}$. e na $12^{\mathrm{a}}$ séries da escola média . Além dos dados coletados sobre os alunos, seus pais, professores e as respectivas escolas, NELS inclui escores em testes cognitivos, equacionados de forma que as medidas são feitas em uma mesma escala, aplicados aos mesmos alunos ao alcançarem cada uma dessas séries escolares. Os dados coletados pelo NELS: 88 são bem apropriados para os fins do presente estudo, pois pode-se estimar os efeitos do tamanho da escola sobre ganhos em rendimento escolar, entre o princípio e o fim do curso médio, com relação a uma grande amostra representativa da população de alunos e de escolas. Focalizamos alunos durante os anos em que cursavam a escola média, de modo que nossa amostra inclui aqueles sobre os quais há dados nas três séries e que permaneceram na mesma escola até se graduarem: um total de 9812 alunos distribuídos por 789 escolas públicas, escolas católicas, assim como pelas melhores escolas particulares que apresentavam dados suficientes para os métodos de análise empregados na pesquisa. Detalhes sobre o método de seleção desta amostra são descritos por Lee, Smith e Croninger (1997).

Na 8a série, tomada como base, o estudo do NELS selecionou alunos nas escolas fundamentais. O plano do estudo determinava que se fizesse o seguimento desses alunos durante seu curso na escola média; entretanto, as escolas médias não foram amostradas diretamente. A amostragem em dois estágios incluiu uma proporção maior de certos tipos de escolas (escolas particulares e escolas que tinham alta proporção de alunos de origem asiática e da América Latina); assim sendo, foi preciso utilizar pesos ao analisar os dados, de modo a se poder generalizar os resultados em relação à população de alunos de escolas médias norte-americanas. O NCES forneceu pesos relativos aos níveis de alunos e de escolas para a amostra da $8^{a}$ série, mas para as demais séries foram fornecidos pesos apenas ao nível de alunos. Como nossas análises focalizam os efeitos da escola, era importante empregar pesos com relação às escolas. Uma das grandes vantagens da amostragem do NELS era sua representatividade, que desejávamos conservar. O problema foi resolvido estabelecendo pesos para as escolas com base em procedimento por nós definido².

Medidas. Neste estudo mede-se a aprendizagem na escola secundária em matemática e leitura. Escolhemos essas duas disciplinas

\footnotetext{
2 Para maiores detalhes sobre este procedimento consulte-se o Apêndice A do artigo de Lee and Smith (1995) ou as Autoras. O método usado no estabelecimento dos pesos para as escolas incluiu as probabilidades de: (a) o tipo de escola que os alunos freqüentaram na $8^{a}$ série, (b) a matrícula total de cada escola média, e (c) os pesos, agregados no nívelaluno, fornecidos pelo NCES. 86 
porque: a) são importantes para o sucesso do aluno no futuro; b) diferem bastante entre si; c) os efeitos da escola podem diferir de uma para outra disciplina. Limitamos nossa investigação a duas disciplinas para simplificar o estudo; a pesquisa do NELS inclui também ciências e história. A medida da aprendizagem se faz em termos de ganhos no rendimento nessas disciplinas entre a $8^{\text {a }}$ série e a $12^{\text {a }}$ série, na qual o aluno termina a escola média. NELS usou, nos escores dos seus testes, uma escala baseada na teoria da resposta ao item (IRT) para capturar o padrão de rendimento dos alunos em termos do número de respostas corretas em itens calibrados em um contínuo de nível estimado de dificuldade e equalizados por série e por formas dos testes. Deste modo, não se tem o efeito de regressão em direção à média que tradicionalmente se observa quando se usa, como medida do ganho, a diferença entre o rendimento em duas medidas sucessivas. Seguimos o conselho de John Willet, para quem o escore representado pela diferença entre duas medidas sucessivas "não é o proscrito que muito críticos proclamam" (1994, p. 673).

Com o acúmulo de informações, os procedimentos de medida melhoraram e a fidedignidade dos escores estimados aumentou, na realidade, passando de 0,80 na $8^{\text {a }}$ série para 0,85 na série seguinte, em leitura e de 0,89 para 0,94 em matemática (NCES, 1995,p.67). Além disso, a validade de constructo dos escores (IRT) estimados foi investigada comparando-se o padrão das correlações dos escores (IRT) dos alunos com outras medidas relevantes de variáveis demográficas e relativas ao seu progresso. Em geral, o procedimento de medida forneceu consistentemente informação fidedigna sobre o nível de rendimento dos alunos em matemática e em leitura nos vários pontos tomados para comparação (NCES, 1995).

A variável independente especialmente focalizada é, evidentemente, o tamanho da escola em termos de matrícula ${ }^{3}$. Neste trabalho, usou-se como medida do tamanho da escola o número de alunos matriculados, embora em estudo anterior tenhamos empregado uma transformação logarítmica desse número. Em uma primeira análise de sensibilidade, tomamos o tamanho da escola como uma medida contínua, cuja distribuição apresenta assimetria positiva bastante acentuada. $\mathrm{Na}$ maior parte das análises, porém, esse contínuo foi dividido em oito categorias: 300 alunos ou menos, 301-600, 601-900, 901-1200, 1201-1500, 1501-1800, 1801-2100, 2100 e acima. Essas categorias foram estabelecidas

\footnotetext{
3 Apoiando-se o estudo em uma medida precisa do tamanho da escola que só é encontrada nos arquivos de dados do NELS, declaramos que as Autoras possuem licenças para usar tais dados do NELS, a primeira com licença do NCES (L-912050011) e a segunda com licença separada, obtida através de sua Universidade.
} 
com base em análises preliminares (descritas abaixo). Em uma delas, partiu-se o contínuo da medida de tamanho das escolas em duas partes (escolas menores e maiores). Outras variáveis incluídas nos modelos como controles estatísticos também são descritas abaixo, juntamente com a apresentação dos modelos analíticos. No Apêndice A são dados detalhes da definição de todas as variáveis usados no estudo.

\section{Modelos Analíticos}

Estimando efeitos do tamanho da escola sobre a aprendizagem, com modelos HLM. A estrutura hierárquica das questões da pesquisa estimativas dos efeitos do tamanho das escolas na aprendizagem dos alunos - aliada à estrutura dos dados do NELS sugere a necessidade de se empregar modelos lineares hierárquicos HLM (Bryk \& Raudenbush,1992). Usamos uma estrutura HLM de dois níveis (conglomerados de alunos dentro de escolas). No Nível 1 (dentro-das-escolas) nosso modelo considera o crescimento do rendimento dos alunos, através de quatro anos na escola média, como função das características dos estudantes. Os resultados estudados nesse nível abrangem tanto a aprendizagem (ganhos no rendimento em matemática e em leitura) como a distribuição eqüitativa desses ganhos (relação entre o nível social da família dos alunos, ou SES, e os ganhos em rendimento escolar). As estimativas do HLM da fidedignidade desses escores, em termos de ganhos (lambda), são respeitáveis: 0,724 (ganhos em matemática) e 0,556 (ganhos em leitura).

Para todas as questões da pesquisa, usamos o mesmo modelo de Nível 1, o qual inclui controles relativos a dados demográficos dos alunos (SES, raça / etnia, gênero) e dados sobre seu nível de habilidade (medidas compostas de rendimento, na $8^{\text {a }}$ série, em outras disciplinas - excluídas matemática e leitura). A variável nível socioeconômico do aluno (SES) é de especial interesse, pois a inclinação da curva de aprendizagem em função do SES é nosso indicador de equidade social dentro das escolas ${ }^{4}$. Nos modelos de Nível 2 (entre-escolas), os resultados estudados são definidos,

4 Na linguagem do HLM o SES é deixado "livre" e as outras variáveis de controle dentroda-escola são "fixas" (isto é, a variabilidade das variáveis fixas é reduzida a zero entre escolas). Assim, a variável SES é centralizada em torno da média do grupo (escola), enquanto gênero, participação em minorias, habilidade geral, são todas centralizadas na média global da amostra. Maiores detalhes sobre o processo são dados por Bryk and Raudenbush (1992). Nós controlamos a posição inicial ou habilidade, nessas análises, computando as médias dos escores $\mathrm{z}$ dos alunos, na $8^{\mathrm{a}}$ série, nos três testes do NELS que cobriam disciplinas dentre as quais não constava aquela que era objeto da análise (por exemplo: a variável habilidade, usada como controle nas análises dos ganhos em matemática, incluía escores, na $8^{\text {a }}$ série, em leitura, ciências e estudos sociais). 
em ambas as disciplinas, pela média de rendimento (Questão 1) e pela inclinação da curva de rendimento em função do SES em cada escola (Questão 2). Os modelos HLM de nível 2 incluem ajustamento estatístico para dados demográficos da escola e tipo da escola, tanto em relação ao rendimento escolar como à sua distribuição eqüitativa. Além do tamanho, os modelos de Nível 2 incluem controles relativos ao SES da escola, à concentração de minorias e ao tipo da escola (pública, católica, particular de elite). No Apêndice A são dadas informações quanto a médias de grupos em todas as medidas incluídas nos modelos.

Análise de sensibilidade. A modelagem de efeitos do tamanho da escola sobre a aprendizagem levou a uma série de análises de sensibilidade. As decisões sobre os pontos de corte entre as oito categorias de tamanho foram guiadas por essas análises. As análises multivariadas de sensibilidade usaram uma técnica multinível residual. De um modelo HLM de dois níveis, semelhante ao descrito acima, conquanto sem a variável tamanho da escola, foram tomados os resíduos relativos aos quatro resultados observados quanto à aprendizagem e à distribuição eqüitativa (ganho médio em rendimento em matemática e em leitura, além de sua distribuição social). Esses resíduos (rendimento ajustado) foram representados graficamente em relação com a medida contínua da variável tamanho da escola. A Figura 1 mostra o gráfico do rendimento residual em matemática em relação à matrícula da escola ${ }^{5}$.

\section{Figura 1}

Distribuição dos resíduos de ganhos de rendimento em matemática, conforme a matrícula na escola média

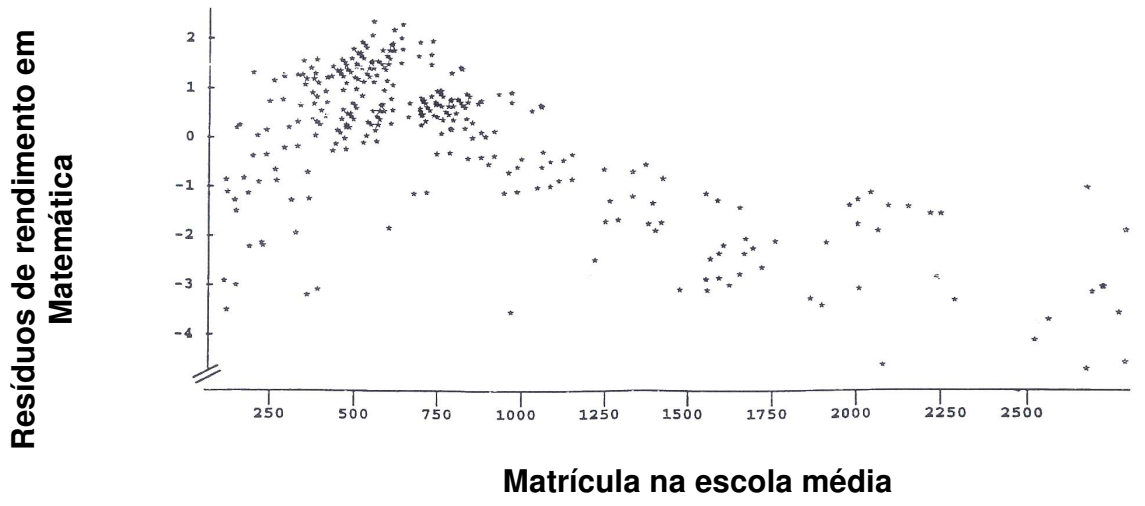

* Resíduo de ganho em matemática, em uma escola

5 Sendo os padrões do rendimento residual em leitura (assim como em ciências e história, que são as outras disciplinas examinadas pelo NELS) bastante semelhantes, não os incluímos aqui, para maior parcimônia. 
O gráfico da Figura 1 indica que o rendimento residual em matemática (isto é, diferenças nas médias dos ganhos das escolas, depois do ajustamento com relação às covariáveis dos níveis de alunos e de escolas) varia conforme o tamanho da escola e também indica que essa relação é curvilínea. O ponto mais alto da curva, nesse gráfico, sugere que há um tamanho ótimo de escola. Escolas cuja matrícula está entre 500 e 1000 alunos parecem estar melhor em termos de rendimento em matemática. Escolas menores do que essas apresentam resultados inferiores. Mais dramático, o rendimento mais baixo é nas escolas maiores. Como as análises das duas disciplinas sugeriam um tamanho ótimo de escola semelhante, omitiu-se o gráfico do rendimento residual em leitura.

De modo geral, as escolas menores se apresentam como mais efetivas em termos da aprendizagem dos alunos. Ficou também evidente que a relação não é linear. Para contornar este problema, ao empregar nossos modelos HLM, a medida contínua do tamanho da escola foi convertida em categorias de 300 alunos/grupo e essas categorias foram codificadas. Para estimar o efeito de um conjunto de variáveis codificadas é preciso selecionar um grupo, o qual passa a ser designado grupo de comparação. Selecionamos a categoria de tamanho da escola entre 1201 1500 alunos. Embora a escolha de um grupo de comparação seja arbitrária, esta categoria foi escolhida porque representa o tamanho médio da escola nesta amostra.

Efeitos diferenciais do tamanho da escola. O efeito do tamanho das escolas é diferente conforme o tipo de alunos que as freqüentam? Parece pouco provável que um só tamanho ótimo seja apropriado para todos os tipos de escolas e de alunos. A Questão 3 aborda a influência do tamanho de escolas que apresentam diferente composição social. Para focalizar a média de nível econômico-social e a concentração de minorias, usamos uma estratégia de análise da interação, ao explorar a possibilidade de efeito diferenciado do tamanho da escola.

Para o nível socioeconômico médio (SES) foi criado um conjunto de efeitos codificados da interação com as categorias de tamanho da escola, os quais foram incluídos no modelo HLM juntamente com as categorias codificadas de tamanho da escola. Como a medida da variável relativa à proporção de alunos pertencentes a minorias nas escolas médias não tem uma distribuição normal, foi criada uma variável dicotômica, com a classe de escolas com $40 \%$ ou mais de alunos de minorias recebendo o código "1" e a classe de escolas com menos de $40 \%$ recebendo o código "0". O resultado dessa codificação da variável "concentração de minorias" foi um grande número de termos de efeitos de interação. Os modelos HLM se mostraram bastante instáveis quando esses efeitos da interação foram 
incluídos nos modelos juntamente com os efeitos principais das categorias de tamanho das escolas. Este problema foi resolvido criando-se dois termos lineares, sendo que em um deles as escolas de matrícula menor do que 900 conservaram a medida contínua do tamanho e as de matrícula maior do que isso receberam o código " 0 ", enquanto no outro termo as escolas de matrícula menor do que 900 receberam código " 0 ", e as de matrícula maior do que 900 conservaram a medida contínua de seu tamanho ${ }^{6}$. Foi, então, computado o produto de cada categoria de tamanho da escola pela categoria de concentração de minorias da escola.

\section{Apresentação dos resultados}

Para todas as variáveis usadas no estudo são apresentadas médias de subgrupos formados por classes de tamanho da escola. Os modelos multivariados empregados para explorar as questões de pesquisa incluíam múltiplas análises quantitativas e, em cada uma delas, um grande número de estimativas quantitativas de efeitos. Decidimos apresentar os resultados em uma forma que minimizasse a quantidade de números e que destacasse os efeitos do tamanho da escola. Assim sendo, decidimos mostrá-los em forma de gráficos. Todos os gráficos que apresentam os efeitos do tamanho da escola foram construídos com base nos modelos HLM integrais descritos acima. Esses modelos incluem ajustamentos estatísticos com relação a um grande número de medidas de controle que descrevem tanto alunos como escolas. Medidas diferentes são usadas para apresentar os efeitos do tamanho da escola. Para responder às Questões 1 e 2 os efeitos são medidos em termos de desvios-padrão (SD) a partir do ponto de comparação, que é o de escolas cuja matrícula está na classe de 1200 a 1500 alunos. Com relação à Questão 3, para cada categoria de tamanho da escola, os resultados são apresentados como médias ajustadas dos ganhos médios em termos de escores, em Matemática e Leitura, obtidos nos testes do NELS . Foi selecionada a forma gráfica de apresentação porque mostra "a história do tamanho da escola" de modo que uma audiência não técnica pode entender facilmente. Para os leitores interessados em detalhes técnicos das análises e nos efeitos das variáveis de controle, os resultados numéricos das análises HLM são apresentados no Apêndice B.

\footnotetext{
${ }^{6}$ Criamos dois termos para a medida da variável tamanho da escola (representando escolas pequenas e grandes). Usamos o tamanho de 900 como ponto de corte para determinar os valores para os dois termos, dado que nossas análises indicavam que 900 estava próximo do tamanho ótimo. Os códigos para os dois termos são descritos no Apêndice A.
} 


\section{Resultados \\ Análises descritivas}

Características dos alunos e das escolas, por tamanho da escola A distribuição das escolas conforme o tamanho é assimétrica positiva, com tamanho mediano igual a cerca de 1200, em nossa amostra do NELS. Embora haja muitas escolas pequenas na amostra, e ainda mais na população, naturalmente, há um número maior de alunos na população que freqüentam escolas grandes do que pequenas. A Tabela 1 apresenta o tamanho das amostras não ponderadas e as médias ponderadas das variáveis incluídas neste estudo, para as oito classes de tamanho da escola. As variáveis são agrupadas conforme descrevam alunos (parte A) ou descrevam escolas (parte B). Na amostragem original do NELS o número de alunos por escola era quase uma constante, de modo que na distribuição, em nossa amostra, o número de alunos amostrados varia pouco pelas categorias de tamanho da escola, o mesmo acontecendo com o número de escolas. Entretanto, há mais alunos e há mais escolas nas categorias de tamanho moderado ${ }^{7}$.

Em geral, a parte A da Tabela 1 mostra que os ganhos na aprendizagem são maiores nas escolas de tamanho moderado ou pequeno, embora não o sejam nas menores de todas. Deve-se considerar que tais escolas matriculam alunos de certo modo mais bem preparados e alunos de nível sócio-econômico (SES) mais alto. Já as escolas variam mais, nas diversas classes de tamanho, quanto aos fatores apresentados na parte B da Tabela 1.

\footnotetext{
7 A amostra aqui é praticamente a mesma usada em nossos estudos sobre a reestruturação das escolas (Lee \& Smith, 1995, 1996; Lee, Smith \& Croninger,1997). Tendo sido empregado o HLM para a análise, nesse estudo, a amostra na 10a. série foi restringida a escolas que tinham pelo menos cinco alunos no estudo do NELS. Este critério de seleção resultou em abandono de muitas escola particulares pequenas (principalmente aquelas com apenas um aluno no estudo do NELS). A amostra do presente estudo, portanto, é um tanto tendenciosa no sentido de favorecer as escolas maiores. Note-se, porém, que o número de escolas pequenas é bastante grande para ser usado no tipo de análise do presente estudo. Todos os alunos que apresentavam escores de testes na $8^{\mathrm{a}}$ série e na $12^{\mathrm{a}}$ série foram incluídos na amostra. Os alunos não incluídos na amostra, através dessas filtragens, eram um tanto mais favorecidos do que os incluídos. Portanto, a tendenciosidade introduzida pelos critérios de seleção dos elementos da amostra leva a subestimar, e não a superestimar, os efeitos observados.
} 
Tabela 1

Médias de variáveis que descrevem alunos e escolas, por categorias de tamanho da escola ( $n=9812$ estudantes em 789 escolas)

\begin{tabular}{|c|c|c|c|c|c|c|c|c|}
\hline \multicolumn{9}{|c|}{ A - Médias de variáveis que descrevem alunos } \\
\hline Tamanho da Escola & $\begin{array}{l}\text { Abaixo } \\
300\end{array}$ & $\begin{array}{c}301 \mathrm{a} \\
600\end{array}$ & $\begin{array}{c}601 \mathrm{a} \\
900\end{array}$ & $\begin{array}{c}901 \mathrm{a} \\
1200\end{array}$ & $\begin{array}{c}1200 \mathrm{a} \\
1500\end{array}$ & $\begin{array}{c}1501 \mathrm{a} \\
1800\end{array}$ & $\begin{array}{l}1801 \mathrm{a} \\
2100\end{array}$ & $\begin{array}{l}\text { Over } \\
2100\end{array}$ \\
\hline Amostra de Alunos & 912 & 830 & 1667 & 1645 & 1319 & 1205 & 1263 & 971 \\
\hline \multicolumn{9}{|l|}{ 1. Resultados } \\
\hline $\begin{array}{l}\text { Ganhos em } \\
\text { Matemática }\end{array}$ & 8.91 & 12.13 & 15.69 & 13.44 & 12.20 & 11.61 & 10.18 & 7.84 \\
\hline Ganhos em Leitura & 4.54 & 6.28 & 7.61 & 6.46 & 5.05 & 4.60 & 4.34 & 3.45 \\
\hline \multicolumn{9}{|l|}{ 2. Variáveis de controle } \\
\hline Habilidade, Mat $^{\mathrm{a}}$ & 0.03 & 0.17 & 0.17 & 0.18 & 0.12 & 0.18 & 0.05 & 0.11 \\
\hline Habilidade, Leit $^{\mathrm{a}}$ & 0.05 & 0.21 & 0.14 & 0.19 & 0.13 & 0.21 & 0.07 & 0.15 \\
\hline$\%$ Sexo feminino & 52.8 & 51.5 & 47.9 & 49.9 & 52.7 & 52.4 & 52.9 & 50.4 \\
\hline$\%$ Minorias & 14.5 & 24.3 & 14.3 & 18.0 & 16.6 & 15.6 & 23.5 & 21.5 \\
\hline $\begin{array}{l}\text { Nível } \\
\text { socioeconômico }\end{array}$ & -0.12 & 0.07 & 0.11 & 0.05 & 0.03 & 0.08 & -0.04 & -0.06 \\
\hline \multicolumn{9}{|c|}{ B - Médias das variáveis que descrevem escolas } \\
\hline Tamanho da Escola & $\begin{array}{c}\text { Abaixo } \\
300\end{array}$ & $\begin{array}{c}301 \mathrm{a} \\
600\end{array}$ & $\begin{array}{c}601 \mathrm{a} \\
900\end{array}$ & $\begin{array}{c}901 \mathrm{a} \\
1200 \\
\end{array}$ & $\begin{array}{c}1200 \mathrm{a} \\
1500\end{array}$ & $\begin{array}{c}1501 \mathrm{a} \\
1800\end{array}$ & $\begin{array}{c}1801 \mathrm{a} \\
2100\end{array}$ & $\begin{array}{l}\text { Over } \\
2100\end{array}$ \\
\hline $\begin{array}{l}\text { Tamanho da amostra } \\
\text { de escola }\end{array}$ & 75 & 67 & 148 & 139 & 83 & 70 & 101 & 106 \\
\hline SES médio ${ }^{b}$ & -0.21 & 0.09 & 0.18 & 0.08 & 0.09 & 0.18 & -0.15 & -0.32 \\
\hline $\begin{array}{l}\text { \% Alta concentração } \\
\text { de minorias }\end{array}$ & 20.3 & 26.9 & 16.3 & 21.2 & 15.8 & 14.5 & 26.1 & 33.3 \\
\hline \% Públicas & 95.0 & 92.5 & 75.5 & 81.2 & 90.8 & 89.4 & 92.8 & 95.9 \\
\hline \% Católicas & 2.5 & 4.5 & 10.9 & 12.2 & 6.6 & 6.6 & 0.9 & 3.1 \\
\hline$\%$ Independentes & 2.5 & 3.0 & 13.6 & 6.6 & 2.6 & 4.0 & 6.3 & 1.0 \\
\hline
\end{tabular}

a - Rendimento médio dos alunos na $8^{\text {a }}$ série nas três disciplinas usadas como medida alternativa de habilidade, com média $(\mathrm{M})=0$ e desvio padrão $(\mathrm{SD})=1$.

b - Medidas das variáveis em escores-padrão $\mathrm{z}$, com $\mathrm{M}=0, \mathrm{SD}=1$ nesta amostra.

c - Não sendo a distribuição normal, foi atribuído o código 1 a escolas com mais de $40 \%$ de alunos pertencentes a minorias (negros ou latinoamericanos) e código 0 às demais escolas.

O nível socioeconômico médio é mais alto nas escolas de tamanho moderado (600-900 a 1500-1800 alunos), aproximando-se da média nas categorias centrais de tamanho, e mais baixo nas escolas de tamanho muito pequeno ou muito grande (diferenças entre grupos abaixo de 0,2 desvios-padrão). Não surpreende que a concentração de minorias seja mais alta nas escolas maiores. Em todas as categorias de tamanho a grande maioria é de escolas públicas; as particulares aparecem mais comumente na categoria de 600-1200 alunos (sendo, porém, menos de 25\% dessa classe), o que pode explicar, nesse grupo, as médias mais altas de nível 
socioeconômico e de habilidade ${ }^{8}$. Essas diferenças apresentadas por classes de tamanho das escolas, tanto quanto a características dos alunos como das escolas, sugerem que é importante levá-las em consideração ao serem estimados os efeitos do tamanho da escola sobre a aprendizagem.

Modelos multivariados: que tamanho de escola apresenta melhores resultados?

Efeitos sobre a aprendizagem, em matemática e em leitura. A Figura 2 apresenta os resultados das análises dos efeitos do tamanho da escola sobre os ganhos em rendimento, em matemática e em leitura, ao cursar a "high school". Os efeitos, apresentados na métrica da magnitude do efeito entre-escolas (desvios-padrão, SD) ${ }^{9}$, foram estimados segundo um modelo HLM de dois níveis que inclui ajustes para todas as características dos alunos e das escolas relacionadas na Tabela 1. Efeitos de tamanho igual ou maior do que $0,5 \mathrm{SD}$, foram interpretados como grandes, entre $0,3 \mathrm{SD}$ e 0,5

8 Tendo os pesos, estabelecidos ao nível-escola, incluído o tamanho da escola como um de seus componentes (ver nota 3), nós comparamos os padrões de ganhos de rendimento, por tamanho da escola, em análises em que esses pesos foram incluídos e naquelas em que não o foram. O Apêndice B-1 mostra comparações das médias dos ganhos de grupos (na métrica dos escores $\mathrm{z}$ ). Os padrões são, em geral, bastante semelhantes, exceto nas escolas menores, nas quais os ganhos não ponderados são um pouco maiores. Observamse desvios-padrão um tanto menores para médias ponderadas do que os das médias nãoponderadas.

${ }^{9}$ Como nossas hipóteses focalizam efeitos da escola, neste estudo, seguimos a orientação de Bryk and Raudenbush (1992, capítulo 5) de manter o foco na magnitude dos efeitos entreescolas. Estes foram computados, para cada categoria codificada de tamanho da escola, dividindo-se os coeficientes gama, relativos aos ganhos em rendimento (ou aos coeficientes de inclinação SES / ganhos), pelo desvio-padrão (SD) entre-escolas, na respectiva disciplina, estimado com o modelo HLM de Nível 1 . Os desvios-padrão estimados com os modelos HLM de Nível 1 são: ganho de matemática, 2,276 ; ganho de leitura, 1,494 ; coeficiente de inclinação SES/ ganhos em matemática, 0,950 ; coeficiente de inclinação SES/ ganhos em leitura, 0,347 (ver Apêndice B-2). O procedimento seguido aqui tem sido usado em muitos outros estudos publicados e que usam o HLM, nos quais os efeitos são comumente apresentados em unidades de desvio-padrão entre-escolas. Veja-se Lee and Bryk(1989), Lee and Smith(1993,1995, 1996), ou Raundebush, Eqmsukkawat, Di-Ibor, Kamali and Taoklam (1993). É claro que o tamanho desses efeitos é maior do que aquele obtido dentro de um conceito mais tradicional, principalmente porque os desvios-padrão entre-escolas usados ao computá-los são menores do que os desvios-padrão estimados no nível-aluno (por exemplo, o desvio-padrão do ganho, em matemática, dentro da escola é 7,78 e, em leitura. é 6,80). Alguns podem preferir interpretar a magnitude do efeito do tamanho da escola na métrica tradicional. Nossos resultados sugerem que o tamanho da escola tem efeitos importantes sobre a aprendizagem em qualquer das métricas. Notamos, entretanto, que é somente a variância entre-escolas a ser explicada pelo tamanho da escola . Assim sendo, usamos estimativas dos tamanhos dos efeitos entre-escolas, nas Figuras 2 - 6, em que nossos resultados são apresentados. 
SD como moderados, de 0,1 SD a 0,3 SD como pequenos e aqueles abaixo de 0,1 SD como triviais (Rosentthal \& Rosnow,1984). Não se menciona a questão da significância estatística porque os contrastes são, de certo modo, arbitrários. Nossa discussão focaliza especialmente as magnitudes relativas dos efeitos do tamanho das escolas mostrados na Figura 2.

Figura 2

Efeitos do tamanho da escola sobre ganhos em Matemática e Leitura

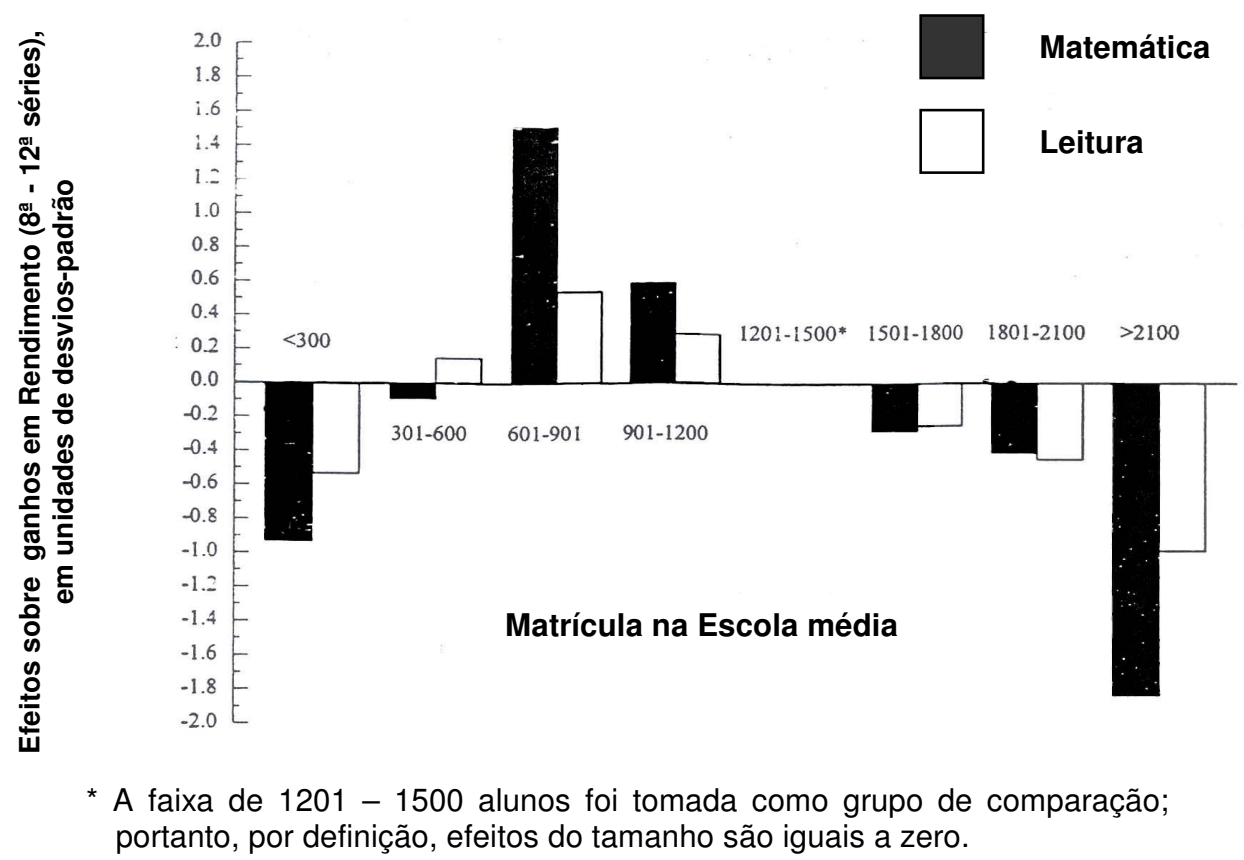

Os efeitos do tamanho da escola são maiores em matemática (barras escuras) do que em leitura (barras claras), embora mostrem uma tendência geral semelhante nas duas disciplinas.Todos os efeitos são comparados com a categoria de tamanho de 1201-1500, a qual, por definição, não tem efeito. Os resultados indicam que os alunos das escolas de matrícula entre 600 e 900 apresentam nível ótimo de aprendizagem. Os ganhos de rendimento são menores nas escolas menores (particularmente naquelas com menos de 300 alunos); o rendimento é também consideravelmente menor nas escolas maiores (com mais de 2100 alunos). O tamanho dos efeitos é grande em matemática (em dois casos, acima de $1 \mathrm{SD}$ ); os ganhos em compreensão de leitura são moderados. Embora a classe de 600-900 alunos contenha número um pouco maior de escolas particulares (cerca de 
um quarto das escolas nessa categoria são particulares), ao se estimar esses efeitos tomou-se em consideração o tipo de escola ${ }^{10}$.

Efeitos na distribuição eqüitativa da aprendizagem. Os efeitos do tamanho da escola e os parâmetros de equidade - coeficientes de inclinação de SES sobre os ganhos em rendimento em matemática e leitura, dentroda-escola - foram estimados simultaneamente conforme os mesmos modelos HLM, sendo que os efeitos sobre a aprendizagem são mostrados na Figura 2. Apresentamos, entretanto, esses efeitos separadamente (coeficientes de inclinação na Figura 3), porque os resultados são um tanto diferentes. Virtualmente, em todas as escolas a relação entre SES e ganhos em rendimento é positiva; os alunos de nível sócio-econômico aprendem mais. Então, por definição, os efeitos de tamanho que são negativos indicam maior equidade, pois refletem uma relação mais fraca entre SES e aprendizagem. De modo geral, o efeito do tamanho das escolas é maior sobre a equidade do que sobre a aprendizagem (principalmente porque é menor o desvio-padrão dos coeficientes de inclinação do SES sobre os ganhos em rendimento, o qual foi usado para estimar esses efeitos, como se descreve na nota 9). Embora os efeitos do tamanho da escola sobre a aprendizagem sejam maiores em matemática do que em leitura, os efeitos sobre a equidade são mais substanciais sobre leitura.

\footnotetext{
${ }^{10}$ Na Tabela 2 são apresentados os diversos valores da variância entre-escolas (tau), partindo do modelo totalmente não-condicional, passando ao modelo dentro-da-escola (Nível 1), depois ao modelo efeitos-do-tamanho (Nível 2), até o modelo integral (de 2 níveis). Esta informação nos permite estimar a proporção da variância explicada em cada estágio. Na Tabela 2, abaixo do valor de cada estimativa da variância, aparece esta proporção estimada, em cada caso, com relação ao valor original da variância entre escolas em cada disciplina estudada.
} 
Figura 3

Efeitos do tamanho da escola sobre a relação entre nível socioeconômico (SES) e ganhos em rendimento em matemática e leitura

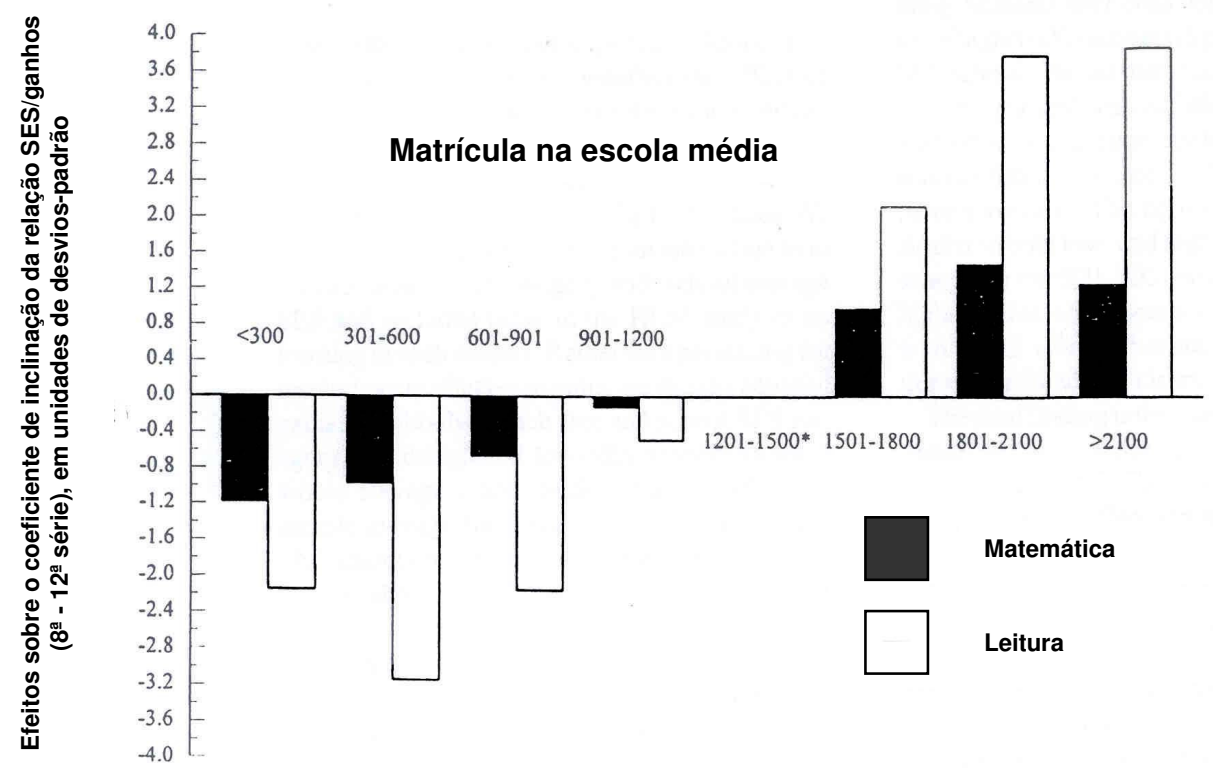

* A faixa de 1201 - 1500 alunos foi tomada como grupo de comparação; portanto, por definição, efeitos do tamanho são iguais a zero.

O padrão da distribuição também é claro, embora um tanto diferente: a aprendizagem é distribuída mais eqüitativamente em escolas menores. De modo geral, é linear a distribuição dos efeitos do tamanho das escolas sobre os coeficientes de inclinação da relação entre SES e ganhos em rendimento escolar, não exibindo uma vantagem especial no caso das escolas de tamanho moderado. Em leitura, nas escolas de tamanho de 300-600 a equidade é maior (tamanho dos efeitos (ES) de cerca de -3 desvios-padrão); em matemática a maior vantagem ocorre nas escolas de menor tamanho (efeitos (ES) de cerca de -1 desvio-padrão). Assim como em relação a efeitos do tamanho da escola sobre ganhos em rendimento, a aprendizagem é distribuída de modo menos eqüitativo nas escolas maiores (especialmente em leitura). Os interessados nos efeitos de cada variável, nos modelos HLM integrais (e nos níveis de significância), podem consultar o Apêndice B - 2 em que são apresentados os resultados numéricos, correspondentes às Figuras 2 e 3, dos Modelos HLM integrais 
de Nível 2 relativamente a ganhos e a coeficientes de inclinação em matemática e leitura11.

Modelos multivariados: que tamanho de escola é mais efetivo e para quem?

Efeitos do tamanho em escolas de alto e de baixo SES. Com o HLM também investigamos se o efeito estimado do tamanho da escola é constante para escolas com diferentes composições sociais. Nossas primeiras análises investigam como os efeitos do tamanho da escola sobre a aprendizagem variam conforme a composição socioeconômica da escola. Para isso, para cada categoria de tamanho da escola, criamos um termo de interação com o SES médio da escola, sendo esses termos incluídos nas análises com o HLM sobre a aprendizagem em cada disciplina. Ao invés de apresentar aqui os resultados em unidades de efeitos do tamanho, mostramos os ganhos ajustados para escolas em cada categoria de tamanho e de SES. São designadas escolas de baixo SES aquelas cujo SES médio está um desvio-padrão abaixo da média de SES das escolas da amostra. E são designadas escolas de alto SES aquelas cujo SES médio está um desviopadrão acima da média das escolas da amostra12. Os resultados dessas análises dos ganhos dos alunos em rendimento em matemática são apresentados na Figura 4. Foi realizada análise idêntica em relação aos ganhos em rendimento em leitura, mas os efeitos da interação não foram

11 O modelo HLM integral, usado na computação dos valores nas Figuras 2 e 3 é apresentado, para matemática e leitura, no Apêndice B - 2. Efeitos não-ponderados do tamanho da escola são apresentados no Apêndice B-3 . Comparando os resultados dos Apêndices B-2 e B-3 chegamos às conclusões seguintes: (1) estimativas não-ponderadas dos efeitos do tamanho da escola são um pouco menores do que as ponderadas; (2) o padrão geral dos efeitos é muito semelhante entre análises ponderadas e não-ponderadas, mesmo sendo as magnitudes um tanto diferentes; (3) as estimativas dos desvios-padrão entre-escolas nas análises HLM de Nível 1 também são maiores nas análises nãoponderadas do que nas ponderadas (também relatado na nota 8). Quais dos resultados é correto? Como argumentamos no texto, a ponderação dos casos no nível-escola é necessária devido ao planejamento da amostragem do NELS . Entretanto, também reconhecemos dificuldades inerentes ao uso dos pesos aqui. Assim sendo, incluímos todos os resultados observados, de modo que o leitor possa concluir por si mesmo.

12 Sendo cada categoria de tamanho codificada na métrica dos efeitos $(1,-1)$, os vários termos de interação foram computados multiplicando-se cada categoria, assim codificada, pela média do SES na escola. Juntamente com o efeito principal do tamanho e com as mesmas variáveis de controle incluídas nas análises correspondentes às Figuras 1 e 2, incluímos o conjunto dos sete termos de interação na análise HLM de Nível 2. Computamos, então a média, para cada categoria de tamanho da escola, combinando os termos apropriados e substituindo, nas equações, seja -1 (para escolas de baixo SES), seja +1 (para escolas de alto SES). Detalhes das operações podem ser obtidos das Autoras. 
significativos. Assim sendo, limitamos nossa discussão aos padrões identificados na aprendizagem de matemática.

Figura 4

Ganhos médios em rendimento em matemática, por tamanho da escola, em escolas de baixo e de alto nível socioeconômico (SES)

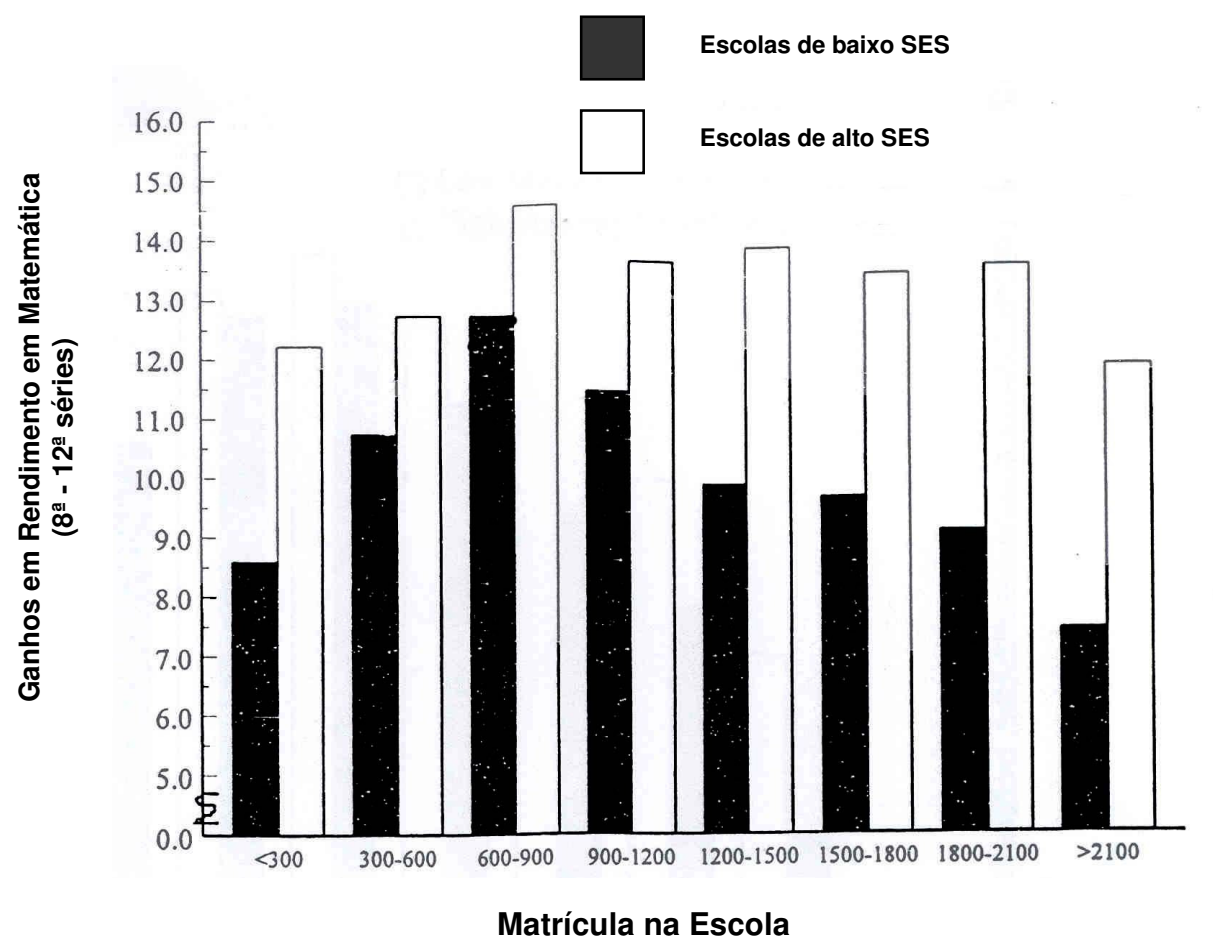

Três resultados ficam evidentes na Figura 4. O primeiro não surpreende, embora mereça destaque e seja perturbador. Os alunos aprendem consideravelmente mais matemática em escolas de alto SES (barras claras) do que em escolas de baixo SES. Note-se que essas diferenças de rendimento são computadas levando-se em conta o ajustamento estatístico para outras características sociais dos alunos e das escolas. O segundo resultado é mais surpreendente. $\mathrm{O}$ tamanho ótimo de escola é bastante semelhante para o nível alto e para o nível baixo de SES da escola. Isto é, escolas na categoria de matrícula de 600-900 apresentam os mais altos ganhos em rendimento em ambos os grupos. O alunos que freqüentam escolas maiores ou menores do que esse tamanho ótimo não apresentam rendimento tão bom em matemática. 
O terceiro resultado é o mais notável e o mais importante. $\mathrm{O}$ tamanho da escola parece fazer mais diferença em relação àquelas freqüentadas por alunos menos favorecidos. Embora as diferenças de rendimento sejam notáveis entre as escolas de alto e de baixo SES que estão na faixa de tamanho de 600-900 (ganho de cerca de 2 pontos em um teste de 40 pontos), em escolas com menos de 300 alunos essa diferença é maior (cerca de 3,5 pontos). Nas escolas maiores as diferenças de aprendizagem são marcantes (cerca de 5 pontos). Consultando a Tabela 1 verifica-se que o nível socioeconômico médio nas escolas muito grandes ou muito pequenas é baixo (nas maiores é de - 0,32 SD e nas menores é de $-0,21 \mathrm{SD})$. Nossos resultados sugerem que grande número de alunos socialmente desfavorecidos freqüentam escolas cujo tamanho é justamente aquele em que os alunos, como eles, parecem aprender menos.

Efeitos do tamanho em escolas com alta e baixa concentração de minorias. Também verificamos se o efeito do tamanho era o mesmo em escolas com alta e baixa concentração de minorias. A distribuição da variável que mede a proporção de alunos pertencentes a minorias (negros e latinoamericanos) nas escolas americanas é bimodal: grande proporção de escolas médias apresentam muito poucos alunos oriundos de minorias; proporção menor de escolas têm a maior parte dos alunos proveniente de minorias. Há relativamente ainda menos escolas no centro da distribuição (escolas mistas ou integradas). Essa distribuição, que reflete a persistência de importante forma de discriminação nas escolas por muitas décadas, sugeriu a criação de uma variável codificada para refletir a concentração de minorias (ver Apêndice A).

Os termos da interação do tamanho da escola com a concentração de minorias são um tanto diferentes. A variável tamanho foi transformada linearmente em dois termos e codificada conforme as escolas fossem grandes ou pequenas (ver a codificação no Apêndice A e Bryk \& Raudenbush, 1992, sobre outra aplicação desses códigos). Computamos os termos do produto destas variáveis com uma forma recodificada da variável representativa da concentração de minorias. Usando os códigos de tamanho da escola, nos dois termos, calculou-se o ganho médio em cada uma das categorias, tanto nas escolas de baixa concentração como nas da alta concentração de minorias. Os resultados da análise HLM para ganhos em matemática são apresentados na Figura 5; os de leitura estão na Figura 6. Em ambas as disciplinas os efeitos da interação entre tamanho da escola e concentração de minorias são estatisticamente significantes. 


\section{Figura 5}

Ganhos médios em rendimento em matemática, por tamanho da escola, em escolas de baixa e alta concentração de minorias na matrícula

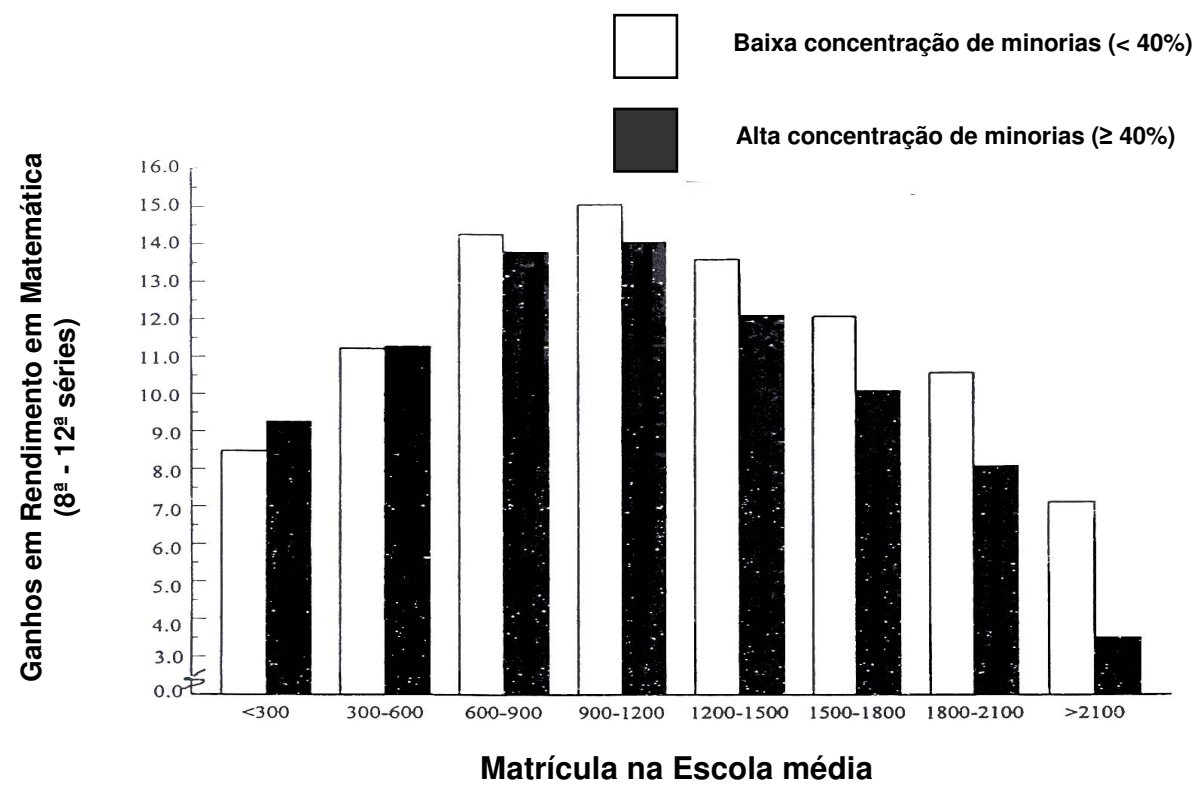

Figura 6

Ganhos médios em rendimento em leitura, por tamanho da escola, em escolas de baixa e de alta concentração de minorias na matrícula

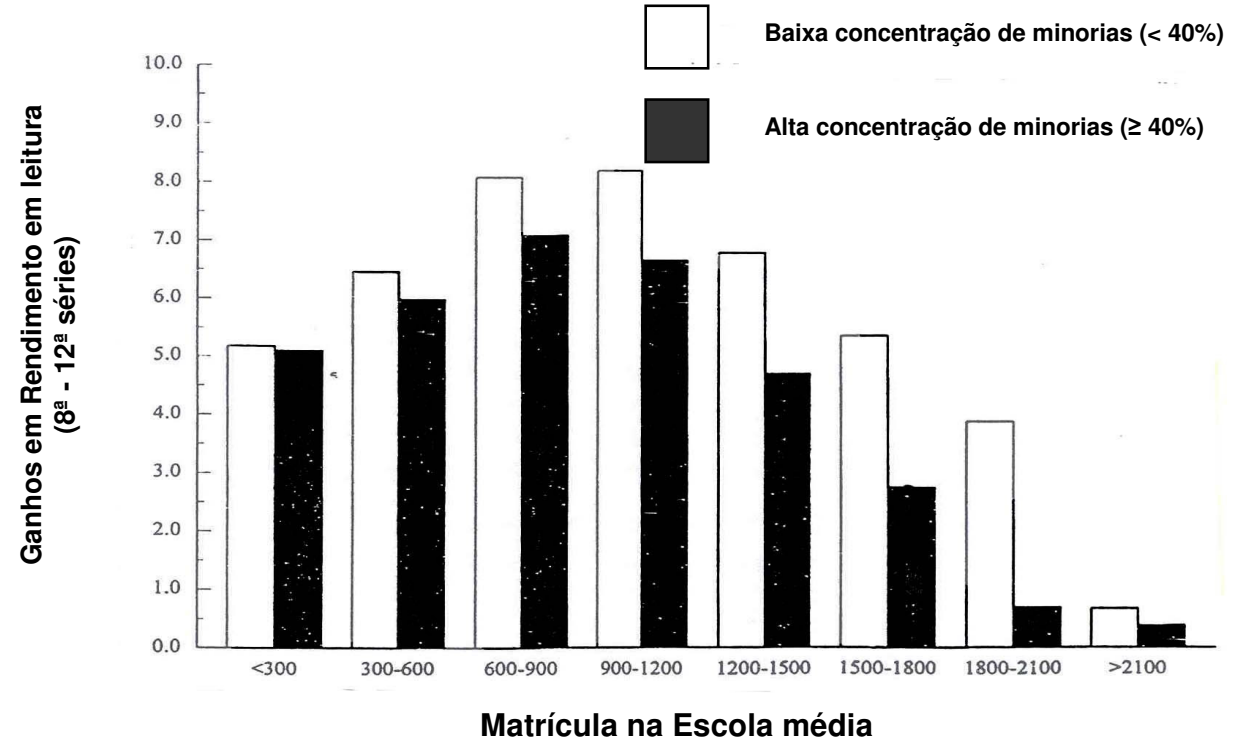




\section{Matemática}

As diferenças de ganhos de rendimento em matemática, entre as escolas com baixa concentração de minorias (barras brancas) e alta concentração (barras pretas) são menos marcantes do que os contrastes entre escolas de nível socioeconômico (SES) diferentes apresentados na Figura 4. Novamente não surpreende (mas perturba) encontrar-se ganhos inferior em matemática em escolas com maior concentração de minorias. Do mesmo modo observado quanto ao nível socioeconômico (SES), o tamanho ótimo da escola é igual tanto para as de alta como as de baixa concentração de minorias, embora aqui o ponto mais alto seja daquelas que matriculam entre 900 e 1200 alunos $^{13}$. Escolas muito pequenas com alta concentração de minorias parecem ter resultados um pouco melhores do que as de baixa concentração. Na Tabela 1 observa-se que as escolas muito pequenas apresentam menos alunos pertencentes a minorias. Como mostram as Figuras 3 e 4, a diferenciação social é maior nas escolas grandes. As escolas muito grandes que têm alta concentração de minorias apresentam ganhos de rendimento muito baixos e as diferenças são maiores nessas escolas. Fica claro que as escolas grandes se constituem em ambientes bastante problemáticos para a aprendizagem, especialmente aquelas cuja matrícula inclui alta proporção de minorias e de alunos de nível socioeconômico inferior.

\section{Compreensão de leitura}

Embora em relação aos ganhos em leitura não se tenha encontrado interação entre tamanho e nível socioeconômico médio da escola em nossas análises, as interações de tamanho com concentração de minorias são estatisticamente significantes (Figura 6). Em geral, a tendência é semelhante em matemática e em leitura. Os alunos de escolas de tamanho entre 600 e 1200 alunos são os de melhor rendimento em leitura nas escolas que têm tanto baixa como alta concentração de estudantes pertencentes a minorias. As diferenças são notoriamente grandes nas escolas maiores. Particularmente nas escolas de alta concentração de minorias que estão na faixa de tamanho acima de 1800 alunos, em média, os ganhos são pequenos em leitura durante o curso na escola média. Nas escolas extremamente grandes, qualquer que seja a concentração de minorias, os ganhos em

13 A localização um pouco diferente do ponto mais alto é provavelmente devida ao uso do ponto de corte escolhido para definir os dois termos do contínuo tamanho da escola: 900 alunos. Daí concentrarmos a análise nos padrões gerais apresentados e não no ponto mais alto observado. 102

Estudos em Avaliação Educacional, n. 25, jan-jun/2002 
rendimento são quase nulos. A magnitude dos ganhos encontrados é menor em leitura do que em matemática; na realidade, trata-se de um reflexo do tamanho relativo das duas provas (21 itens em leitura e 40 itens em matemática).

\section{Discussão \\ Efeitos do tamanho da escola na aprendizagem}

Os resultados do presente estudo são resumidos em quatro conclusões gerais sobre o tamanho ótimo das escolas médias. "Ótimo" é definido em termos do rendimento dos alunos em compreensão de leitura e em matemática . A discussão é organizada como se descreve a seguir. Primeiro apresentamos as conclusões que emergem diretamente do estudo, reportando-nos às Figuras 2 - 6. Segue-se um resumo de recomendações sobre o tamanho da escola derivadas de literatura importante sobre a escola média. Terminamos com uma discussão sobre temas, que são fundamentais quanto à relação entre tamanho da escola e a aprendizagem.

Conclusão 1: As escolas médias deveriam ter tamanho menor do que o de muitas delas atualmente .Os resultados das análises hierárquicas multivariadas levam em consideração muitas características demográficas dos alunos e características estruturais das escolas, além do tamanho da escola. Os resultados apresentados na Figura 2 mostram claramente que os alunos de escolas médias de tamanho moderado estão à frente em aprendizagem, ainda que os efeitos do tamanho da escola não sejam iguais nas duas disciplinas investigadas. Os efeitos do tamanho também diferem, de certo modo, quanto à efetividade (isto é, níveis de rendimento escolar) e quanto à equidade (isto é, distribuição do rendimento conforme o nível socioeconômico dos alunos). A Figura 3 sugere que as escolas menores têm distribuição mais eqüitativa. Concluímos, com segurança, que muitas escolas médias deveriam ser menores do que atualmente são, se quisermos maximizar a aprendizagem nas escolas do país. Os alunos aprendem mais em escolas relativamente pequenas; a aprendizagem é distribuída mais eqüitativamente em escolas pequenas.

Conclusão 2: As escolas médias podem ser demasiado pequenas. Uma das motivações para o presente estudo era investigar a atual tese da política educacional de que escolas médias de menor tamanho são melhores. Como já foi mencionado, parece lógico que escolas médias podem ser demasiado pequenas para poder oferecer programas acadêmicos adequados aos alunos (a não ser que as bases de recursos sejam muito altas e a clientela seja bastante homogênea). Os resultados mostrados na Figura 2 confirmam isso. Os alunos aprendem menos em escolas com matrícula abaixo de 600 
alunos, assim como também acontece em escolas muito grandes. Entretanto, o rendimento escolar é distribuído mais eqüitativamente em escolas muito pequenas. É óbvio que os objetivos de efetividade e de equidade não são inteiramente paralelos. Em termos gerais, considerando tanto a efetividade como a equidade, nossos resultados nos levam a recomendar um tamanho entre 600 e 900 alunos como ideal para uma escola média.

Conclusão 3: O tamanho ideal não varia conforme o tipo de alunos matriculados. Algumas de nossas análises investigam se nossa recomendação quanto ao tamanho ideal deve ser generalizada por escolas que diferem quanto às características socioeconômicas de seus alunos. Esta questão é importante porque há uma tendência dos alunos menos favorecidos socialmente a freqüentar escolas que são muito grandes ou demasiado pequenas (ver Tabela 1). Nossas pesquisas procuram verificar se escolas menores ou escolas maiores seriam preferíveis quando se consideram os tipos diferentes de estudantes que as freqüentam. Focalizamos escolas que diferem quanto ao nível social e quanto à concentração de minorias. De certo modo, verificamos com surpresa o mesmo padrão de resultados: escolas de tamanho moderado (600 - 900 alunos) apresentam maiores ganhos em rendimento, tanto no caso daquelas de baixo ou de alto SES, como no caso daquelas de baixa ou de alta concentração de minorias. Portanto, nossa recomendação quanto ao tamanho ideal da escola média (Conclusão 2) se aplica a todas as escolas, qualquer que seja a origem social ou cultural de seus alunos.

Conclusão 4: O tamanho é mais importante para alguns tipos de escolas. Embora o tamanho da escola seja um fator importante na determinação da aprendizagem dos alunos em geral, parece ser mais relevante para alguns alunos do que para outros. Nossos resultados indicam que o tamanho da escola é importante particularmente para os alunos menos favorecidos socialmente. As Figuras 4 e 6 revelam que o rendimento desses alunos decresce rapidamente à medida que o tamanho das escolas que eles freqüentam é maior ou menor do que o tamanho ideal. Esses resultados são importantes porque estudantes pertencentes a minorias tendem a freqüentar escolas grandes, e estudantes de nível socioeconômico inferior têm maior probabilidade de serem encontrados em escolas grandes ou em escolas muito pequenas (a Tabela 1 mostra isso). Achamos que esta conclusão é de especial importância se queremos aumentar a equidade social nos resultados das escolas médias norte-americanas. 


\section{O tamanho das escolas, segundo textos populares}

O tema do tamanho da escola tem recebido bastante atenção em trabalhos teóricos e em artigos não-acadêmicos, assim como em relatórios defendendo idéias sobre as reformas a serem introduzidas nas escolas. A pesquisa empírica sobre o tópico, porém, nem é sólida nem numerosa. Embora tenha sido feita uma revisão dos trabalhos empíricos relevantes no início deste artigo, ao refletir sobre os resultados encontrados em nossa pesquisa fomos levados a considerar uma amplitude maior de trabalhos sobre o assunto. Nossas conclusões sobre o tamanho ideal da escola média parecem estar alinhadas com recomendações de outras fontes acadêmicas que, entretanto, não são derivadas diretamente de análises empíricas. Um exemplo é o de James Bryant Conant, que é reconhecidamente o pai da escola média compreensiva. Em 1959, em seu livro sobre a escola média norte-americana, de tanta influência, Conant escrevia que uma escola que tivesse uma classe de graduação de 100 alunos deveria ser suficientemente grande para implementar o currículo recomendado (embora preferisse escolas um pouco maiores do que isso). Obviamente, as atuais escolas médias compreensivas são consideravelmente maiores do que esse tamanho mínimo de Conant.

John Goodlad escreveu sobre as escolas médias quase três décadas depois de Conant. Em "A Place Called School" ele comentava: "O ônus da prova, parece-me, cabe ao tamanho grande. Na realidade, eu não gostaria de enfrentar o desafio de defender uma escola média de mais de 500 a 600 alunos (a não ser que quisesse argumentar a favor de uma forte equipe de futebol, em vez de uma boa escola, coisa que não desejo fazer)" (Goodlad,1984,p.310). Em um ensaio sobre tamanho da escola e o desenvolvimento do adolescente, Garbarino (1980) defende a importância particular do tamanho da escola no caso de alunos cujas características se afastam da zona mediana . Fazendo eco aos estudo de Barker e Gump (1964), ele descreveu um efeito de limitação, pelo qual são mínimas as vantagens do aumento do tamanho das escolas acima de cerca de 500 alunos. Nem Conant, nem Goodlad, nem Garbarino oferecem evidência empírica sobre o tamanho de escola que defendem.

Já Bryk, Lee and Holland, explorando o tema dos efeitos diferenciados do tamanho da escola em relação a estudantes de origem social diversificada, apresentam evidência empírica de que a influência é maior sobre a equidade social do que sobre o rendimento escolar em escolas médias católicas ou públicas. Sem fazer uma recomendação específica, eles concluem: "É simples, é mais fácil criar uma estrutura acadêmica internamente diferenciada em uma escola maior" (Bryk et 
al.,1993,p.270). Embora a Coalition for Essential Schools não tenha recomendações específicas sobre o tamanho da escola, Theodore Sizer, em "Horace's Compromise", incluiu "conservar a estrutura simples e flexível" entre os cinco "imperativos para as escolas melhores" (1984, p.114).

Nos últimos anos, a Carnegie Foundation patrocinou dois relatórios muito influentes sobre a reforma educacional. Seu relatório de 1989, "Turning Points" enumerou políticas para mudar as escolas fundamentais. A primeira recomendação era "criar pequenas comunidades para a aprendizagem" (Carnegie Council on Adolescent Development, 1989, p.9). O relatório não deu orientações explícitas sobre o tamanho das escolas fundamentais, mas destacou itens considerados essenciais, como "escolas dentro de escolas ou casas". A mais recente manifestação da Carnegie Foundation sobre reformulação da política educacional é o relatório de 1996, "Breaking Ranks". Usando a palavra "personalização", terminologia idêntica a um princípio importante da Coalition for Essential Schools, o primeiro dos seis principais itens recomenda que "As escolas médias devem subdividir-se em unidades de não mais do que 600 alunos, de modo que professores e alunos possam conhecer-se mutuamente"(NASSP, 1996,p.5).

Um livro recente e popular descreveu uma reforma radical em Filadélfia, onde 90 pequenas unidades escolares ("charter") foram criadas dentro das 22 escolas médias compreensivas da cidade (Fine, 1994). Embora as pequenas unidades escolares da Filadélfia fossem, de certo modo, especializadas (como, tipicamente, tais unidades escolares são), a tônica geral do livro é, decididamente, a favor de escolas médias pequenas e enfatiza o ambiente de sentimento de grupo estimulado dentro delas. A descrição de um professor sobre o efeito do aumento do tamanho (de 200 para 400 alunos) dessas pequenas unidades escolares é típica do professorado dessas escolas: -"As costuras das pequenas unidades escolares ("charter") parecem demasiadamente distendidas"(p.131). A principal preocupação, porém, é com a deterioração das relações sociais dentro da escola e entre grupos de professores e alunos. A aprendizagem não era um ponto relevante no livro de Fine.

Esses trabalhos, cuja maioria é bem recente, destacam consistentemente o tema: as escolas médias deveriam ser menores do que são. Nossa primeira conclusão apóia essa idéia. Um pressuposto importante das sugestões para reduzir-se o tamanho da escola média é o de que as relações humanas nas escolas menores seriam mais pessoais. Ficamos admirados com a consistência das recomendações sobre o tamanho ideal (600 alunos parece ser muito popular), embora ao fazermos um exame minucioso desses trabalhos encontrássemos escassa base 
empírica para essa recomendação específica. Certamente não é toda recomendação de política educacional que requer o suporte de evidência empírica específica (algumas se fundamentam em sólidos princípios morais). Ficamos, porém, conjeturando sobre qual a maneira pela qual esses autores chegaram a tais recomendações específicas e consistentes.

Também ficamos surpresos com o fato desses trabalhos não parecerem ter reconhecido que uma escola média poderia ser demasiado pequena. Embora nossos resultados convirjam para esse mesmo tamanho ideal, também sugerem que escolas muito pequenas podem não trazer vantagens para a aprendizagem dos alunos. Caso o objetivo a alcançar fosse promover a equidade social, ou facilitar as relações pessoais, então "quanto menor melhor" seria provavelmente uma conclusão correta. Entretanto, é difícil deixar de reconhecer que o principal objetivo da escola, em geral, e da escola média, em particular, é (e defendemos a idéia de que deve ser) promover a aprendizagem dos alunos. Assim sendo, ficamos a conjecturar sobre a razão pela qual esses autores não se preocuparam com um tamanho demasiado pequeno.

Importância dos resultados para a prática e para a política educacional

Uma relação de causalidade? Um tamanho menor da escola é realmente "causa" dos alunos aprenderem melhor? Embora a estrutura de nossas análises sobre a relação do total da matrícula com o rendimento do aluno pudesse implicar em "causalidade", somos cautelosos quanto a concluir sobre uma relação direta de causalidade entre o número de alunos da escola e o rendimento escolar. Preferimos levantar a hipótese de que o tamanho da escola funciona como um fator que facilite, ou que dificulte, a ação de formas organizacionais ou práticas, as quais, por seu turno, promovem a aprendizagem dos alunos.

No princípio deste artigo descrevemos duas teorias conflitantes sobre o tamanho da escola, uma das quais focaliza o currículo. Aumentando o tamanho, fica mais fácil oferecer um currículo diversificado, o que redunda em uma diferenciação do conteúdo dos programas oferecidos - para melhor corresponder às diferenças individuais. Mencionamos que em escolas menores (particularmente nas católicas) há maior probabilidade de ser oferecido um currículo comum, que todos (ou a maioria dos alunos) devem seguir, quaisquer que sejam suas habilidades ou aspirações. Este tipo de currículo responde mais a necessidades comuns a todos do que a diferenças individuais. Como nossos resultados favorecem as escolas menores (mas não as demasiado pequenas), sugerimos que haja um equilíbrio, que possa levar a uma 
variedade suficiente de programas para servir adequadamente os alunos, mas não tão grande que amplie a diferenciação.

Outro foco teórico dos trabalhos sobre tamanho da escola é o das relações sociais. Esta teoria é claramente a favor das escolas pequenas; as relações sociais entre membros da escola (professores entre si, ou entre professores e administradores) tendem a maior coleguismo e a ser mais pessoais (entre professores e alunos ou entre todos os membros da escola). Goodlad (1984) levantou outra questão importante para a política educacional e que interessa aos integrantes das escolas assim como às comunidades em que se situam: sustentar equipes de esportes de alto nível. A despeito de sua importância para muitos dos que estão ligados às escolas norte-americanas, nós hesitamos em elevar esta preocupação ao nível de tema teórico. De outro lado, as atividades extra-curriculares em qualquer escola média, assim como a participação dos alunos nessas atividades, constituem elemento importante das experiências na escola. E essas atividades dependem certamente do tamanho da escola. Na realidade, é razoável a hipótese de que o tamanho da escola tem influência sobre muitos outros objetivos a alcançar, além do desenvolvimento cognitivo como, por exemplo, relações sociais, compromisso do aluno com a aprendizagem, auto-estima, senso de participação, participação em atividades extra-curriculares e papel de liderança. Além disso, o tamanho ideal da escola é provavelmente diferente para o alcance de outros objetivos. No presente estudo, entretanto, focalizamos a atenção na aprendizagem em duas disciplinas durante o curso na escola média.

Embora a relação direta entre tamanho da escola e rendimento escolar encontre suporte em nossas análises, pode-se argumentar seguindo uma lógica diferente. É mais provável que nossos resultados sobre o tamanho da escola representem uma explicação, que serve de alternativa à da influência de aspectos básicos da organização e do funcionamento das escolas médias: características do currículo, relações entre os membros da escola, e atividades extra-curriculares. Nós estamos nos ocupando, numa pesquisa de campo, do modo pelo qual o tamanho influencia esses aspectos estruturais. Sugerimos que os efeitos do tamanho da escola sobre a aprendizagem, que apresentamos aqui, sejam compreendidos como provavelmente indiretos, mediados por sua influência sobre aspectos fundamentais da organização acadêmica e social e do funcionamento das escolas (variáveis não incluídas em nossos modelos). Nessa explicação o tamanho das escolas serve como um fator de facilitação, ou de inibição, em relação a processos educacionais fundamentais. De outro lado, os responsáveis por políticas educacionais podem argumentar que é mais fácil mudar o tamanho da escola do que alterar aspectos organizacionais 
(principalmente quando tal mudança não envolve o custo de construir novas escolas).

Resultados de pesquisas empíricas podem realmente influenciar políticas públicas. O tamanho da escola e seus efeitos sobre os alunos é um tópico que o público, em geral, pode compreender. Neste caso as políticas sociais podem estar em confronto com sólidas pesquisas empíricas. A recente série de artigos de primeira página do New York Times (Dillon,1995; Dillon \& Berger, 1995; Firestone, 1995; Gonzales, 1995) apresenta histórias interessantes sobre algumas das 46 pequenas escolas experimentais de New York abertas nos dois anos anteriores. O principal critério para definir essas escolas é o pequeno tamanho (na faixa de 110 a 600 alunos). Refletindo sobre um dos temas que mencionamos - relações sociais Joseph A. Fernandez, o "chancellor" anterior do New York City Schools, ao lançar a campanha por alterações em 1992, criticou:- "Nossas escolas médias eram demasiado grandes e havia muitos problemas com crianças que sentiam que as pessoas nem sabiam quem elas eram"(Dillon \& Berger,1995,p. B-11). Segundo os artigos do Times, 50 outras pequenas escolas estavam nos planos em New York, com suporte financeiro para a campanha de US\$ 50 milhões doados por Amemberg Foundation a New York City. No "movimento das pequenas escolas", New York e Filadélfia são apenas duas das muitas cidades que o integram.

Esses movimentos, em que alterações são introduzidas sem o suporte da pesquisa empírica, sugerem que: (a) é oportuna a investigação empírica sobre o tópico, (b) há uma extraordinária receptividade, entre os responsáveis por decisões práticas, em relação a resultados de pesquisas que lhes ofereçam apoio, ainda que "post-hoc" (as mudanças freqüentemente ocorrem antes dos resultados das pesquisas serem divulgados). Esses acontecimentos na política educacional também indicam que o movimento na direção das escolas pequenas, na realidade, pode resultar em uma quantidade de escolas demasiado pequenas para serem efetivas em relação à aprendizagem dos alunos. Este é um tema sobre o qual os acadêmicos não têm muito a argumentar sobre a importância da pesquisa para mobilizar profissionais da educação em prol da reforma. Neste caso particular, os esforços na direção da reforma já se fazem aceleradamente.

Como mudar o tamanho da escola? O experimento em New York (com o generoso apoio de uma Fundação) representa claramente uma das abordagens para alterar o tamanho médio da escola: criar novas escolas (ou escolas menores dentro dos limites de uma grande já existente). Nossos resultados sugerem que essa abordagem, abrindo muitas escolas demasiado pequenas pode não ser a melhor. De fato, a série de reportagens 
do New York Times destaca vários problemas nessas escolas. Tendo em vista a presente situação fiscal e o modesto apoio público para investimentos (financeiro ou psicológico) em melhoramentos sociais, parece pouco provável que os distritos escolares americanos embarquem em uma campanha para abrir muitas escolas novas pequenas. Isso é pouco provável especialmente nas maiores cidades, nas quais os recursos financeiros são particularmente escassos.

Uma alternativa razoável à construção de novas escolas é um movimento para criar pequenas escolas-dentro-de-escolas maiores. Um tal movimento está brotanto atualmente ${ }^{14}$. Essa política nos parece uma abordagem razoável para dividir grandes unidades escolares, que nosso estudo mostra serem especialmente problemáticas em relação ao rendimento dos alunos. Entretanto sugerimos alguns cuidados, que os responsáveis pelas políticas educacionais devem tomar, se querem adotar uma abordagem de subdivisão interna das grandes escolas para reduzir seu tamanho. Primeiro, é muito importante que o tamanho exato das unidades a serem criadas seja considerado. Nossa pesquisa sugere que unidades demasiado pequenas podem ser problemáticas. Nossas conclusões sobre o "tamanho ótimo" devem ser levadas em consideração. Segundo, preocupa-nos a decisão de criar escolas-dentro-de-escolas, pois parece-nos que poderia ser usada para criar uma série de "estabelecimentos especializados" (Powell, Farrar \& Cohen, 1985), que acabariam por estabelecer diferenças entre alunos e as respectivas experiências na escola média conforme sua habilidade geral, seu objetivo vocacional, ou por outros meios organizacionais. Nossa preocupação é que este tipo de especialização, nas unidades menores possa levar a maior estratificação nas oportunidades e nos resultados das experiências escolares, um "efeito

14 Em estudo anterior (Lee \& Smith, 1995), usamos estimativas lineares dos efeitos do tamanho da escola. Nesse estudo sugerimos que os responsáveis pela política educacional deveriam considerar a organização de escolas-dentro-de-escolas (SWS) como um modo eficiente de reduzir o tamanho da escola. Solicitou-se aos diretores das escolas do NELS que indicassem se realmente haviam adotado essa política em 1990, de modo que investigamos se o tamanho da escola estava relacionado à adoção dessa política (isto é, se os diretores estavam declarando o tamanho da unidade menor ou da maior). Nossos resultados mostram que essa política era um fenômeno essencialmente ligado a escolas públicas (quase nenhuma escola particular declarou aderir ao SWS). Dentre as 672 escolas públicas de nossa amostra, 86 (ou 13\%) optaram pelo SWS. Estas eram escolas maiores (tamanho médio de 1691 alunos), em comparação com as que não optaram pelo SWS (tamanho médio de 1275 alunos). Embora as escolas que adotaram o SWS tivessem maior concentração de minorias ( $34 \%$ versus $24 \%$ ), as escolas públicas que optaram e que não optaram pelo SWS são muito semelhantes quanto a rendimento escolar médio inicial e quanto ao SES médio. 
colateral" que, acreditamos, deva ser evitado. Pelo contrário, cada unidade pequena deveria refletir a diversidade demográfica da escola maior.

\section{Tamanho da escola e alunos menos favorecidos}

Encerramos chamando a atenção para a importância particular do tamanho da escola com relação aos alunos economicamente menos favorecidos e para aqueles que pertencem a minorias. Nos E.U.A. a política educacional e a legislação deixam ao nível da comunidade local as decisões sobre quais as escolas a serem freqüentadas por quais alunos. Mais comumente o acesso às escolas tem por base a localização da residência do aluno. Deve-se considerar que a segregação residencial está aumentando nos E.U.A. e não diminuindo com o passar do tempo (Farley \& Frey, 1994) e, na realidade, a segregação por raça e classe social vem sendo, de modo geral, aparentemente aceita pelo público norte-americano. Alunos de cor, assim como aqueles de origem familiar de baixo nível socioeconômico tendem a estar concentrados em grandes escolas públicas nos E.U.A., em grandes grupos mais ou menos homogêneos (pelo menos demograficamente). Nossos resultados sugerem que o tamanho da escola é muito mais importante, em relação à aprendizagem, justamente em escolas com alta concentração de alunos menos favorecidos. Portanto escolas com muitos alunos, sejam de baixo nível socioeconômico, sejam pertencentes a minorias (muitas vezes escolas com ambos os tipos de alunos), deveriam ficar especialmente interessadas em reduzir o tamanho das unidades nas quais seus alunos realmente aprendem.

Os resultados deste estudo, no mínimo, sugerem que o tamanho da escola média influencia diretamente e/ou indiretamente o quanto seus alunos aprendem. Nossos resultados favorecem a escola de tamanho moderado, nem demasiado pequena a ponto de tornar pouco adequadas aos alunos as experiências curriculares oferecidas, nem tão grande que alguns alunos trilhem um caminho descendente através de fendas oferecidas nos diferentes currículos, o que resulta em experiências curriculares socialmente estratificadas. Os alunos que, com maior probabilidade, passam através das aberturas oferecidas pelos currículos diferenciados e acabam com um programa de nível acadêmico inferior são justamente aqueles socioeconomicamente e culturalmente menos favorecidos. E nossos estudos indicam que tais estudantes são exatamente aqueles em relação aos quais o "tamanho ideal" da escola média é mais importante. 


\title{
APÊNDICE A
}

Descrição das variáveis e medidas usadas no estudo da relação entre tamanho da escola e aprendizagem

\author{
Medidas dos ganhos de rendimento, como variáveis dependentes \\ Ganhos de rendimento
}

Ganho em matemática, entre a $8^{a}$ e a $12^{a}$ séries, foi definido pela diferença de escores entre:

$>$ BY2XMIRR - estimativa do número de itens IRT corretos, em matemática ( $8^{\mathrm{a}}$ série).

$>$ F22XMIRR - estimativa do número de itens IRT corretos, em matemática $\left(12^{\mathrm{a}}\right.$ série).

Ganho em leitura, entre a $8^{\mathrm{a}}$ e a $12^{\mathrm{a}}$ séries, foi definido pela diferença de escores entre:

BY2XRIRR - estimativa do número de itens IRT corretos, em leitura ( $8^{\text {a }}$ série).

F22XRIRR - estimativa do número de itens IRT corretos, em leitura (12 ${ }^{\mathrm{a}}$ série).

\section{Tamanho da escola}

F1C2 - matrícula total em outubro de 1989. Relatório do diretor da escola sobre o tamanho da escola (colhido do arquivo do NELS relativo à escola).

> Categorias de tamanho das escolas (300 e abaixo, 301-600, 601-900; 9011200, 1201-1500, 1501-1800, 1801-2100, acima de 2100) foram estabelecidas com base em F1C2.

> Divisão do contínuo de tamanho das escolas em duas partes, formando os dois termos, como se segue. Primeiro, a matrícula central de 900 foi fixada (isto é, do número total da matrícula de cada escola subtraiu-se 900). No primeiro termo linear, representando as escolas menores, a medida é contínua até 0 e, acima desse ponto, as escolas recebem o código 0 . Representando as escolas maiores, no segundo termo as escolas com menos de 900 alunos recebem o código 0, e a medida é contínua acima desse ponto. Para computar os valores apresentados na Figura 6 (de modo a serem comparáveis com os de outras figuras neste artigo), as médias foram recomputadas, retomando seus valores brutos. 
Variáveis de controle

Variáveis do aluno (controles dentro-da-escola)

Posição socioeconômica

> F2SES1 - posição socioeconômica em um composto expresso em escores $\mathrm{z}$.

Membro de minorias

$>$ F2RACE1 - raça do aluno (códigos: 0=branco ou asiático, 1=negro, latino-americano ou norte-americano nativo).

Gênero

$>$ F2SEX - sexo do aluno (códigos: $0=$ masculino, $1=$ feminino).

Controles acadêmicos

As análises incluíram controles diferentes para as duas disciplinas. Os controles foram formados do modo seguinte:

> Ganho em matemática: soma de BYTXRIRS, BYTXHIRS, BYTXSIRS expressa em escore $Z$.

$>$ Ganho em leitura: soma de BYTXMIRS, BYTXHIRS, BYTXSIRS expressa em escore $Z$.

Variáveis demográficas e estruturais da escola (controles entre-escolas)

Posição socioeconômica média

$>$ AVSES - composto dos SES, agregado ao nível da escola.

Concentração de minorias

$>$ F1RACE - agregado de raça dos alunos (códigos: 0=branco ou asiático, 1=negro, latino-americano ou norte-americano nativo), ao nível da escola e recebendo os códigos: $1=40 \%$ ou mais de minorias, e $0=$ menos de $40 \%$ de minorias.

Tipo de escola

Criado com base em G10CTRL2, medida de controle da escola, no arquivo de escolas do primeiro "follow-up" do NELS. As escolas públicas, católicas ou NAIS (membros da National Association of Independent Schools) foram usadas no estudo; outras escolas particulares foram excluídas. Foram criadas duas variáveis codificadas:

> Católicas - escolas católicas receberam código 1, escolas públicas e NAIS receberam código 0 .

> NAIS - escolas NAIS receberam código 1, escolas públicas e católicas receberam código 0 . 


\section{APENDICE B - 1}

Ganhos médios em Leitura e Matemática, ponderados e não-ponderados, por categoria de tamanho da escola

\begin{tabular}{|c|c|c|c|c|}
\hline \multirow{2}{*}{$\begin{array}{c}\text { Categoria } \\
\text { de tamanho }\end{array}$} & \multicolumn{2}{|c|}{ Ganhos em Matemática } & \multicolumn{2}{|c|}{ Ganhos em Leitura } \\
\hline & $\begin{array}{c}\text { Não-ponderado } \\
\text { M (SD) }\end{array}$ & $\begin{array}{l}\text { Ponderado } \\
\text { M (SD) }\end{array}$ & $\begin{array}{c}\text { Não-Ponderado } \\
\text { M (DP) }\end{array}$ & $\begin{array}{c}\text { Ponderado } \\
\text { M (DM) }\end{array}$ \\
\hline \multirow{2}{*}{$\begin{array}{l}300 \text { ou } \\
\text { menos }\end{array}$} & -0.87 & -0.66 & -0.34 & -0.26 \\
\hline & $(0.38)$ & $(0.28)$ & $(0.83)$ & $(0.74)$ \\
\hline \multirow{2}{*}{$301-600$} & -0.09 & -016 & 0.07 & 0.05 \\
\hline & $(0.24)$ & $(0.18)$ & $(0.80)$ & $(0.78)$ \\
\hline \multirow{2}{*}{$601-900$} & 1.37 & 1.38 & 0.52 & 0.49 \\
\hline & $(0.63)$ & $(0.56)$ & $(0.94)$ & $(0.86)$ \\
\hline \multirow{2}{*}{$901-1200$} & 0.61 & 0.68 & 0.48 & 0.44 \\
\hline & $(0.16)$ & $(0.16)$ & $(0.88)$ & $(0.86)$ \\
\hline \multirow{2}{*}{$1201-1500$} & 0.07 & 0.10 & 0.14 & 0.19 \\
\hline & $(0.19)$ & $(0.16)$ & (0.99) & $(0.88)$ \\
\hline \multirow{2}{*}{$1501-1800$} & -0.16 & -0.09 & -0.08 & 0.06 \\
\hline & $(0.28)$ & $(0.24)$ & $(0.96)$ & $(0.96)$ \\
\hline \multirow{2}{*}{$1801-2100$} & -0.50 & -0.58 & -0.46 & -0.45 \\
\hline & $(0.22)$ & $(0.19)$ & $(0.81)$ & $(0.76$ \\
\hline \multirow{2}{*}{$\begin{array}{l}2100 \text { e } \\
\text { acima }\end{array}$} & -1.57 & -1.59 & -0.77 & -0.89 \\
\hline & $(0.67)$ & $(0.56)$ & $(0.92)$ & $(0.88)$ \\
\hline
\end{tabular}


APENDICE B - 2

Modelo HLM entre-escolas para investigar os efeitos do tamanho da escola sobre ganhos em matemática e leitura ${ }^{a}$

( $n=9812$ estudantes e 789 escolas)

\begin{tabular}{|c|c|c|}
\hline & \multicolumn{2}{|c|}{ VARIÁVEIS DEPENDENTES } \\
\hline & $\begin{array}{c}\text { Ganhos em Matemática } \\
\left(8^{\mathrm{a}}-12^{\mathrm{a}} \text { séries }\right)\end{array}$ & $\begin{array}{c}\text { Ganhos em Leitura } \\
\left(8^{\mathrm{a}}-12^{\mathrm{a}} \text { séries }\right)\end{array}$ \\
\hline \multicolumn{3}{|c|}{ Efeitos entre escolas sobre a média de rendimento (intercepto) } \\
\hline Estimativa global $^{\mathrm{b}}$ & $12.847^{\star \star \star}$ & $5.813^{\star \star \star}$ \\
\hline SES médio ${ }^{c}$ & $0.408^{\star \star \star}$ & $0.262^{\star \star \star}$ \\
\hline Alta concentração de minorias & $0.217^{\star \star \star}$ & -0.013 \\
\hline Escola Católica & 0.790 & -0.093 \\
\hline Escola NAIS & -0.023 & -0.365 \\
\hline \multicolumn{3}{|l|}{ Tamanho da escola $^{d}$} \\
\hline 300 ou menos & $-0.931^{\star \star \star}$ & $-0.532^{\star}$ \\
\hline $301-600$ & -0.089 & 0.149 \\
\hline $601-900$ & $1.512^{\star \star \star}$ & $0.539^{\star}$ \\
\hline $901-1200$ & $0.589^{\star \star \star}$ & 0.290 \\
\hline $1501-1800$ & -0.152 & -0.254 \\
\hline $1801-2100$ & $-0.415^{\star \star}$ & $-0.455^{\star}$ \\
\hline Acima de 2100 & $-1.842^{\star \star \star}$ & $-0.911^{\star \star \star}$ \\
\hline \multicolumn{3}{|c|}{ Efeitos sobre a relação entre SES e ganhos (coeficiente de inclinação) } \\
\hline Estimativa global $^{b}$ & $1.656^{\star \star \star}$ & $1.387^{\star \star \star}$ \\
\hline SES médio ${ }^{c}$ & $0.342-$ & -0.720 \\
\hline Alta concentração de minorias & -0.361 & -0.043 \\
\hline Escola Católica & -0.213 & -1.092 \\
\hline Escola NAIS & -0.161 & -1.382 \\
\hline \multicolumn{3}{|l|}{ Tamanho da escola $^{d}$} \\
\hline 300 ou menos & -1.187 & -2.161 \\
\hline $301-600$ & $-0.985^{\star \star \star}$ & $-3.153^{\star}$ \\
\hline $601-900$ & $-0.667-$ & $-2.156^{\star}$ \\
\hline $901-1200$ & -0.123 & -0.487 \\
\hline $1501-1800$ & $0.984^{\star \star}$ & $2.115^{\star}$ \\
\hline $1801-2100$ & $1.481^{\star \star \star}$ & $3.795^{\star \star}$ \\
\hline Acima de 2100 & $1.264^{\star \star}$ & $3.876^{\star \star}$ \\
\hline \multicolumn{3}{|l|}{ SD computado pelo HLM } \\
\hline Intercepto & 2.276 & 1.494 \\
\hline Coeficiente de inclinação SES/ganhos & 0.950 & 0.347 \\
\hline
\end{tabular}

$p \leq 10 . * 0 \leq 0,05, * * p \leq .001, * * * 0 \leq .001$

${ }^{a}$ Esses efeitos HLM são estimados usando-se os pesos construídos para o nível - escola, conforme descrito na nota 3.

b Resultados HLM computados com ajustamentos dentro-da-escola para SES, pertencente ou não a minorias, gênero, habilidade na $8^{\mathrm{a}}$ série.

c Todos os efeitos (exceto os valores médios relativos ao intercepto e coeficientes de inclinação SES/ganhos) são apresentados na métrica do tamanho padronizado. Efeitos computados dividindo-se os coeficientes gama HLM de cada resultado pelo respectivo desvio-padrão (SD) no nível - escola, computado segundo os modelos HLM Nível 1. Os valores desses desvios-padrão aparecem na faixa inferior desta tabela.

${ }^{d}$ Todos os efeitos do tamanho das escolas são comparados com a categoria de matrícula de 1200 - 1500 alunos, a qual é a categoria excluída. 


\section{APENDICE B - 3}

Estimativas HLM não ponderadas dos efeitos do tamanho da escola sobre ganhos em matemática e leitura ${ }^{a}(n=9812$ alunos e 789 escolas)

\begin{tabular}{|c|c|c|}
\hline & \multicolumn{2}{|c|}{ VARIÁVEIS DEPENDENTES } \\
\hline & $\begin{array}{c}\text { Ganhos em Matemática } \\
\left(8^{\mathrm{a}}-12^{\mathrm{a}} \text { séries }\right)\end{array}$ & $\begin{array}{c}\text { Ganhos em Leitura } \\
\left.\text { (8 } 8^{\mathrm{a}}-12^{\mathrm{a}} \text { séries }\right)\end{array}$ \\
\hline \multicolumn{3}{|c|}{ Efeitos, entre-escolas, sobre a média dos ganhos em rendimento (intercepto) ${ }^{b}$} \\
\hline \multicolumn{3}{|l|}{ Tamanho da escola ${ }^{c}$} \\
\hline 300 ou menos & $-0.292^{\star}$ & 0.417- \\
\hline $301-600$ & -0.469 & 0.038 \\
\hline $601-900$ & $0.473^{\star \star \star}$ & $0.630^{\star \star \star}$ \\
\hline $901-1200$ & $0.347^{*}$ & $0.588^{\star \star *}$ \\
\hline $1501-1800$ & -0.130 & 0.012 \\
\hline $1801-2100$ & $-0.341^{*}$ & $-0.320^{\star}$ \\
\hline Acima de 2100 & $-0.574^{\star}$ & $-0.564^{\star \star}$ \\
\hline \multicolumn{3}{|c|}{ Efeitos sobre a relação SES/ganhos (coeficiente de inclinação) ${ }^{b}$} \\
\hline \multicolumn{3}{|l|}{ Tamanho da escola $^{c}$} \\
\hline 300 ou menos & $-1.220^{\star}$ & -1.113 \\
\hline $301-600$ & -0.571 & -1.666 \\
\hline $601-900$ & $-0.651-$ & -0.967 \\
\hline $901-1200$ & $-0.602-$ & -1.382 \\
\hline $1501-1800$ & $0.571-$ & 0.005 \\
\hline $1801-2100$ & $0.736^{\star}$ & 1.937- \\
\hline Acima de 2100 & $0.786^{\star}$ & $2.859^{\star *}$ \\
\hline \multicolumn{3}{|l|}{ SD computado pelo HLM } \\
\hline Intercepto & 1.494 & 1.451 \\
\hline Coeficiente de inclinação SES/ganhos & 0.347 & 0.398 \\
\hline
\end{tabular}

$p \leq .10 .{ }^{*} p \leq .05 .{ }^{* \star} p \leq .01 .{ }^{* \star *} p \leq .001$.

${ }^{a}$ Esses modelos HLM incluem todas as variáveis dos modelos HLM descritos neste artigo (Nível 1; SES, gênero, raça/etnia, e habilidade na $8^{\text {a }}$ série; Nível 2: SES médio na escola; concentração de minorias, tipo católica e tipo NAIS).

b Como no Apêndice B - 2, todos os efeitos do tamanho são apresentados na métrica do tamanho do efeito padronizado. Efeitos computados dividindo-se o coeficiente gama HLM para cada resultado pelo respectivo desvio-padrão (SD) no nível - escola, apresentado na faixa inferior desta tabela. Note-se que estes são um tanto inferiores àqueles computados nas análises HLM usando os pesos construídos para o nível - escola, mostrados no Apêndice B - 2 .

c Todos os efeitos do tamanho da escola são comparados com a categoria de matrícula 1200 - 1500 alunos, a qual é a categoria excluída. 


\section{APENDICE B - 4}

\section{Modelo HLM entre escola investigando os efeitos, sobre ganhos em Matemática, das interações entre tamanho da escola e SES médio ( $n=9812$ alunos e 789 escolas)}

\begin{tabular}{|c|c|}
\hline & $\begin{array}{c}\text { Ganhos em Matemática } \\
\left.\text { ( } 8^{\mathrm{a}}-12^{\mathrm{a}} \text { séries }\right)\end{array}$ \\
\hline \multicolumn{2}{|c|}{ Efeitos entre-escolas sobre a média de ganhos em matemática (intercepto) } \\
\hline Estimativa global $^{b}$ & $10.733^{\star \star *}$ \\
\hline SES médio ${ }^{c}$ & $0.593^{*}$ \\
\hline Alta concentração de minorias & $0.653^{* *}$ \\
\hline Escola Católica & $-1.793^{* * *}$ \\
\hline Escola NAIS & -0.100 \\
\hline \multicolumn{2}{|c|}{ Efeitos principais do tamanho da escola ${ }^{d}$ (efeitos codificados) } \\
\hline 300 ou menos & $-0.740^{\star \star *}$ \\
\hline $301-600$ & -0.075 \\
\hline $601-900$ & $0.889^{* * *}$ \\
\hline $901-1200$ & $0.334^{\star *}$ \\
\hline $1501-1800$ & -0.171 \\
\hline $1801-2100$ & $-0.277-$ \\
\hline Acima de 2100 & -1.117 \\
\hline \multicolumn{2}{|c|}{ Termos de interação entre tamanho da escola e SES médio $^{d}$} \\
\hline$<300 \times$ AVSES & -0.089 \\
\hline $301-600 \times$ AVSES & $-0.496^{* *}$ \\
\hline $601-900 \times$ AVSES & $-0.541^{* *}$ \\
\hline $901-1200 \times$ AVSES & $-0.446^{*}$ \\
\hline $1501-1800 \times$ AVSES & -0.056 \\
\hline $1801-2100 \times$ AVSES & 0.119 \\
\hline$>2100 \times$ AVSES & 0.144 \\
\hline
\end{tabular}

$p \leq .10 .{ }^{*} p . \leq 05 .{ }^{* \star} p \leq .01{ }^{\star * \star} p \leq .001$

a Esses efeitos HLM são estimados usando os pesos construídos no nível - escola, como se descreve no texto e na nota 3. Embora esta análise também tenha incluído estimativas relativas ao coeficiente de inclinação SES/ganhos, assim como aos correspondentes efeitos dos termos de interação, os resultados obtidos não são apresentados aqui. Não foram encontrados efeitos significativos de interações sobre o coeficiente de inclinação SES/ganhos.

- Os resultados HLM foram computados com ajustamentos dentro-da-escola para SES, pertencente ou não a minorias, gênero e habilidade na $8^{\text {a }}$ série.

• Todos os efeitos são apresentados como coeficientes gama do HLM não ajustados e não como tamanho dos efeitos. Como se descreve na nota 10, para considerar os termos de interação balanceados, as categorias de tamanho das escolas foram registrados na métrica dos códigos dos efeitos (1, -1), e não com a codificação empregada em outras análises neste artigo $(1,0)$. Os termos da interação foram criados como produtos do SES médio da escola e do indicador do tamanho da escola expresso em (1, -

1). Os ganhos médios em matemática apresentados na Figura 4 foram computados calculando-se os efeitos principais e os termos de interação para cada categoria de tamanho, separadamente, no nível inferior de SES das escolas (1 SD abaixo da média) e no nível de SES superior (1SD acima da média), como explicado no texto.

${ }^{\mathrm{d}}$ Todos os efeitos do tamanho das escolas são comparados com a categoria de matrícula de $1.200-1.500$ alunos, a qual é a categoria excluída. 


\section{APENDICE B - 5}

Tabela 2

Estimativas de variâncias para modelos - HLM sucessivos

\begin{tabular}{||c||c|c||c|c||}
\hline \multicolumn{1}{|c|}{ Resultado } & $\begin{array}{c}\text { Modelo não- } \\
\text { condicional } \\
\text { Variância }\end{array}$ & $\begin{array}{c}\text { Modelo } \\
\text { dentro-da- } \\
\text { escola } \\
\text { Variância } \\
\text { (explicada) }\end{array}$ & $\begin{array}{c}\text { Modelo } \\
\text { efeitos-do- } \\
\text { tamanho } \\
\text { Variância } \\
\text { (explicada) }\end{array}$ & $\begin{array}{c}\text { Modelo } \\
\text { HLM } \\
\text { Integral } \\
\text { Variância } \\
\text { (explicada) }\end{array}$ \\
\hline \hline Matemática & 7.003 & 5.221 & 4.344 & 2.295 \\
\cline { 2 - 5 } & $(--)$ & $(0.254)$ & $(0.380)$ & $(0.672)$ \\
\hline \hline Leitura & 4.025 & 2.884 & 2.737 & 2.088 \\
\hline
\end{tabular}

Nota

Uma primeira versão deste artigo foi apresentada em 1996 na reunião anual da American Educational Research Association em New York. Esta pesquisa foi financiada com uma doação da American Educational Research Association, que recebe fundos da National Science Foundation e do National Center for Education Statistics (U.S. Department of Education) para seu AERA Grants Program sob o NSF Grant no. 9452861. As opiniões das Autoras não refletem necessariamente as daqueles que apóiam o estudo. Agradecemos os comentários de Richard Shavelson a um primeiro esboço deste artigo e a ajuda de Anthony Bryk nas análises de sensibilidade descritas neste trabalho.

\section{Referências Bibliográficas}

BARKER, R.; GUMP. R. Big School, Small School: High School Size and Student Behavior. Stanford, Ca.: Stanford University Press,1964.

BIDWELL, C.; KASARDA, J. School Distric Organization and Student Achievement. American Sociological Review, 1975,40(1), 55-70.

BRYK,A. S.; DRISCOLL, M. E. The School as Community: Theoretical Foundations, Contextual Influences, and Consequences for Students and Teachers. Madison, WI.: Center of Effective Secondary Schools, University of Wisconsin, 1988. 
BRYK, A. S.; LEE, V. E.; HOLLAND, P. B. Catholic Schools and the Common Good. Cambridge,MA.: Havard University Press, 1993.

BRYK, A. S.; RAUDENBUSH, S. W. Hierarchical Linear Models: Applications and Data Analysis Methods. Newbury Park, CA.: Sage,1992.

BUZACOTT, J. A. Scale in Production Systems. New York: Pergamon,1982.

Carnegie Council on Adolescent Development. Turning Points: Preparing American Youth for the 21st. Century. New York: Carnegie Corporation, June,1989.

CHAMBERS, J. G. An Analysis of School Size Under a Voucher System, Educational Evaluation and Policy Analysis,1981, 3, 29-40.

CONANT, J. B. The American High School Today. New York: McGraw-Hill, 1959.

DILLON, S. Islands of Change Create Friction, New York Times, May 25, 1995,p. A1, A 15.

DILLON, S.; BERGER,J. New Schools Seeking Small Miracles, New York Times, May 22, 1995, p. A1, B 11.

FARLEY, R.; FREY, W. H. Changes in the Segregation of Blacks and Whites, American Sociological Review, 1994, 59(91), 23-45.

FINE, M. (Ed.). Chartering Urban School Reform: Reflections on Public High Schools in the Midst of Change. New York: Teachers College Press, 1994.

FIRESTONE, D. When Teachers Unite to Run School, New York Times, May 24, 1995, p.A1, A 12.

FOX, W. F. Reviewing Economics of Size in Education, Journal of Education Finance, 1981, 6, 273-296,

FRIEDKIN, N. E.; NECOCHEA, J. School Size and Performance: A Contingency Perspective, Educational Evaluation and Policy Analysis, 1988, 10(3), 237-249.

GAMORAN, A. Measuring Curriculun Differentiation, American Journal of Education, 1989, 97, 129-143.

GARBARINO, J. Some Thoughts on School Size and its Effects on Adolescent Development, Journal of Youth and Adolescence, 1980, 9(1), 19-31.

GARET, M. S.; Delaney, B. Student's Courses and Stratification, Sociology of Education, 1988, 61, 61-77. 
GONZALES, D. A Bridge from Hope to Social Action, New York Times, May 23, 1995, p.A1, A14.

GOODLAD, J. I. A Place Called School: Prospects for the Future. New York: McGraw-Hi ll, 1984.

GOSS, D. Principles of Human Resource Management. New York: Routledge, 1994.

GUTHRIE, J. Organizational Scale and School Success, Educational Evaluation and Policy Analysis, 1979, 1(1), 17-27.

KENNY, L. Economies of Scale in Schooling, Economics of Education Review, 1982, 2(1), 1-24.

LEE, V. E.; BRYK, A. S. Curriculum Tracking as Mediating the Social Distribution of High School Achievement, Sociology of Education, 1988, 61(2), 78-94.

LEE, V. E.; BRYK, A. S. A Multilevel Model of the Social Distribuition of High School Achievement, Sociology of Education, 1989, 62, 172-192.

LEE, V. E.; BRYK, A. S.; SMITH, J. B. The Organization of Effective High Schools. In L. Darling - Hammond (Ed.), Review of Research in Education. Washington D.C.: American Educational Research Association, 1993, Vol. 19, p.171-267.

LEE, V. E.; SMITH, J. B. Effects of School Restructuring on the Achievement and Engagement of Middle-Grade Students, Sociology of Education, 1993, 66(3), 164-187.

LEE, V. E.; Smith, J. B. Effects of School Restructuring and Size on Gains in Achievement and Engagement for Early Secondary School Students, Sociology of Education, 1995, 68(4), 271-290.

LEE, V. E.; SMITH, J. B. Collective Responsibility for Learning and its Effects on Gains in Achievement for Early Secondary School Students, American Journal of Education, 1996, 104(2), 103-147.

LEE, V. E.; SMITH, J. B.; CRONINGER, R. G. How High School Organization Influences the Equitable Distribution of Learning in Mathematics and Science, Sociology of Education, 1997, 70(2), 129-152.

MICHELSON, S. Equal School Resource Allocation, Journal of Human Resources, 1972, 7, 283-306.

MONK, D. Secondary School Size and Curriculum Comprehensiveness, Economics of Education Review, 1987, 6, 137-150. 
MONK, D.; HALLER, E. J. Predictors of High School Academic Course Offerings: The Role of School Size, American Educational Research Journal, 1993, 30, 3-21.

MOROCCO, J. C. The Relationship Between Size of Elementary Schools and Pupil's Perceptions of Their Environment, Education, 1978, 98, 451-454.

MORRISON, C. A Microeconomic Approach to the Measurement of Economic Performance: Productive Growth, Capacity Utilization, and Related Performance Indicators. New York: Springer-Verlag, 1993,

National Association of Secondary Schools Principals (NASSP). Breaking Ranks: Changing an American Institution. Reston, VA: Author, in partnership with the Carnegie Foundation for Advancement of Teaching, 1996.

National Center for Education Statistics (NCES). National Education Longitudinal Study of 1998: Psychometric Report for the NELS:98 Base Year Through Second Follow-up (BCES-95-382). Washinton D.C.: U.S. Department of Education, Office of Educational Research and Improvement, 1995.

OAKES, J. Keeping Track: How Schools Struture Inequality. New Haven,CT: Yale University Press, 1985.

POWELL, A. G.; FARRAR, E.; COHEN, D. K. The Shopping Mall High School: Winners and Losers in the Educational Marketplace. Boston: HoughtonMifflin, 1985.

RAUDENBUSH, S. W.; EAMSUKKAWAT, S.; DI-IBOR, I.; KAMALI, M.; TAOKLAM, W. On the Job Improvement in Teacher Competence: Policy Options and Their Effects on Teaching and Learning in Thailand, Educational Evaluation and Policy Analysis, 1993, 15(3), 279-297.

ROSENTHAL, L.; ROSNOW, R. L. Essentials of Behavioral Research: Methods and Data Analysis. New York: McGraw-Hill, 1984.

SIZER, T. R. Horace's Compromise: The Dilemma of the American High School. New York: Houghton-Mifflin, 1984.

WEBER, M. Theory of Social and Economic Organization (A. M. HENDERSON \& T. PARSONS, Trans.). New York: Mcmillan, 1947.

WILLET, J. B. Change, Measure of. In T.Husen \& T.N. Postlethwaite (Eds.) The International Encyclopedia of Education (2a. ed.). London: Pergamon, 1994, Vol.2 p.671-678. 